\title{
LA PLANIFICACIÓN ENERGÉTICA Y SU SOMETIMIENTO A EVALUACIÓN AMBIENTAL ESTRATÉGICA ${ }^{()}$
}

\author{
Ángel Ruiz De ApodACA EsPinosa \\ Profesor titular de Derecho Administrativo \\ Universidad de Navarra \\ aruiz@unav.es
}

Recibido: 1 de abril de 2010 / Aceptado: 12 de mayo de 2010

RESUMEN: Uno de los sectores con un mayor impacto ambiental lo constituye la generación de energía. Se trata de un sector en el que la planificación previa tradicionalmente ha tenido una gran importancia con el fin de garantizar el suministro, en unos casos con un carácter vinculante y en otros con carácter indicativo. En nuestros días al necesario proceso de planificación se le suma la preceptiva evaluación ambiental estratégica de los diferentes planes y programas energéticos aprobados por cada una de las Administraciones, dado que constituyen el marco de ulteriores proyectos sometidos a evaluación de impacto ambiental.

RESUM: Un dels sectors amb més impacte ambiental és la generació d'energia. Es tracta d'un sector en què la planificació prèvia tradicionalment ha tingut una gran importància per garantir el subministrament, en uns casos amb un caràcter vinculant $\mathrm{i}$ en altres amb caràcter indicatiu. En els nostres dies al necessari procés de planificació s'hi suma la preceptiva avaluació ambiental estratègica dels diferents plans i programes energètics aprovats per cadascuna de les administracions, ja que constitueixen el marc d'ulteriors projectes sotmesos a avaluació d'impacte ambiental.

\footnotetext{
(.) El presente trabajo se enmarca dentro del Proyecto de investigación Gobernanza en los procedimientos administrativos de gestión del riesgo DER 2008-04154/JURI, financiado por el Ministerio de Ciencia e Innovación.
} 
ABSTRACT: One of the sectors with more environmental impact is the production of energy. It is a sector where the previous planning has had traditionally great importance, in order to guarantee the supply, in some cases compulsorily, in other cases merely in an indicative way. Nowadays to the necessary planning process it is added the mandatory strategic environmental assessment of the different energy plans and programs, approved by each public power, provided that they constitute the framework for subsequent projects submitted to environmental impact assessment.

PALABRAS CLAVE: Planificación energética - medio ambiente - evaluación ambiental estratégica.

PARAULES CLAU: Planificació energètica - medi ambient - avaluació ambiental estratègica.

KEYWORDS: Energy planning — environment — strategic environmental assessment.

Sumario: I. La planificación. 1. Concepto. 2. Previsión constitucional. II. Planificación energética. 1. Concepto y marco normativo 2 .Competencia en materia de planificación energética. 3. Objetivos de la planificación energética: el objetivo ambiental. 4. Clases de Planificación. 4.1. Antecedentes. 4.2. La planificación energética vinculante. 4.3. La planificación energética indicativa. 5. Aspectos formales de la planificación energética: procedimiento, carácter normativo e impugnabilidad. 5.1. Antecedentes. 5.2. Procedimiento de aprobación y carácter normativo. 5.3. Impugnabilidad. 5.4. Impugnación por la falta de cumplimiento de las previsiones establecidas en un plan. III. La Planificación energética como capítulo destacado en el proyecto de ley de economía sostenible. IV. La evaluación ambiental de planes y programas energéticos. 1. Introducción, concepto y regulación. 2. La normativa autonómica en materia de EAE. 3. Ámbito de aplicación: inclusión de los planes energéticos. 3.1. Revisiones menores de la planificación. 3.2. Concurrencia de los planes energéticos con otros planes sectoriales o autonómicos. V. El Procedimiento de Evaluación Ambiental Estratégica y su imbricación en la actual planificación energética estatal. 1. El informe preliminar y su alcance: "scoping" o consultas previas. 2. El informe de sostenibilidad ambiental. 3. La necesaria información y participación públicas: alegaciones e informes. 4. La Memoria Ambiental y su inimpugnabilidad. 4.1. Elaboración y carácter no vinculante para el promotor. 4.2. Inimpugnabilidad. 5. Toma de decisión: propuesta de Plan o Programa. 6. Información sobre la decisión: publicidad. 7. Supervisión o seguimiento y ausencia de un régimen sancionador. VI. Conclusión. VII Bibliografía. 


\section{LA PLANIFICACIÓN}

\section{La planificación como concepto}

La planificación es una de las formas de actividad de las Administraciones Públicas con un fin concreto, intervenir la economía o determinados sectores en una sociedad en aras a satisfacer determinados intereses o necesidades públicas, a la consecución de los fines e intereses públicos que tiene encomendados ${ }^{1}$. Se configura como un instrumento fundamental en manos de las Administraciones Públicas para intervenir en la actividad económica ya sea estimulándola, interviniéndola o incluso limitándola.

La planificación es una forma de actividad más de las Administraciones Públicas como medio para hacer efectivos sus objetivos en el corto o medio plazo interviniendo sobre distintas actividades. Como toda actividad administrativa que produce efectos ad extra, la planificación tiene una indudable relevancia jurídica y no se trata de un mero instrumento medial en la actividad de la Administración ${ }^{2}$. GARCÍA DE ENTERRÍA define los planes administrativos como "actos complejos que incorporan un diagnóstico de la situación, un pronóstico de su evolución, un cuadro de prioridades y objetivos y un programa sistemático de acción en función de aquéllos, pudiendo asegurar globalmente la convergencia imprescindible de las distintas acciones, sin la cual no puede conseguirse el óptimo de eficacia en ningún sistema ${ }^{3}$."

Desde un punto de vista energético y sobre todo ambiental, el concepto de planificación no difiere de los ya señalados, si bien en el Derecho ambiental, como señala LOZANO CUTANDA, la planificación se considera una técnica imprescindible debido a su indiscutible utilidad como elemento preventivo de gestión ambiental y coordinación ${ }^{4}$.

\footnotetext{
1 Sobre la planificación administrativa, véase HOPPE, W. "Planificación", Documentación Administrativa. El Derecho Administrativo en Alemania. Tendencias Actuales, núm. 235-236, 1993, pp. 163-249.

${ }^{2}$ Sobre estas cuestiones en el ámbito energético, véase in totum GONZÁLEZ ESPEJO, A. "Cuestiones jurídicas asociadas a la planificación energética” en La nueva regulación eléctrica. VII Jornadas jurídicas del sector eléctrico, Civitas, Madrid, 2002, pp. 17-55.

${ }^{3}$ GARCÍA DE ENTERRÍA, E. y FERNÁNDEZ RODRÍGUEZ, T.R., Curso de Derecho Administrativo, Vol. I, Civitas, Madrid, $2001^{10}$, p. 331.

${ }^{4}$ LOZANO CUTANDA, B., Derecho Administrativo Ambiental, Dykinson, Madrid, $2008^{9}$, p. 385.
} 


\section{Previsión constitucional}

El artículo 131 CE señala que "El Estado mediante Ley podrá planificar la actividad económica general para atender las necesidades colectivas, equilibrar y armonizar el desarrollo regional y sectorial y estimular el crecimiento de la renta y de la riqueza y su más justa distribución". Del mismo modo, el artículo 38 CE in fine hace una referencia a la planificación al reconocer la libertad de empresa "Se reconoce la libertad de empresa en el marco de la economía de mercado. Los poderes públicos garantizan y protegen su ejercicio (...) de acuerdo con las exigencia de la economía general, y en su caso, de la planificación." La referencia del artículo 38 CE a las exigencias en su caso, de la planificación supone una limitación a la libertad de empresa. Dentro de esta planificación se incluyen tanto la general estatal del artículo $131 \mathrm{CE}$, como la sectorial (estatal o autonómica) que también limita la libertad de empresa en el sector económico ${ }^{5}$ y en cierto modo también en el sector energético pese a tener un mero carácter indicativo sobre las decisiones empresariales.

\section{LA PLANIFICACIÓN ENERGÉTICA}

\section{Concepto y marco normativo: la LSE y la LSH}

Además de la planificación económica general a la que hace referencia el artículo $131 \mathrm{CE}$, no menos importante y relacionada también con ella está la profusa planificación sectorial. Evidentemente este precepto constitucional referido a la planificación económica general no impide la planificación de sectores económicos concretos como es el energético. Si el Estado puede abordar la planificación económica general, evidentemente puede utilizar esta técnica para sectores concretos como el energético.

El profesor MARTÍN MATEO define los planes energéticos, como aquellos que tras analizar y valorar la realidad, efectúan una proyección temporal, escalonada, sectorializada de la demanda energética, proponiendo para su cobertura el logro de una serie de objetivos que incluyen el ahorro energético, la racionalización del consumo, la previsión de los recursos y todo ello sobre la base de alternativas previamente seleccionadas en las que se contemplan aspectos cualitativos y cuantitativos, con especial

\footnotetext{
${ }^{5}$ Cfr. GÓMEZ MONTORO, A.J., LÓPEZ-JURADO, F.B., "Los principios constitucionales referidos al ordenamiento jurídico español”, Becker, F., Cazorla, L.M., Martínez-Simancas, J., Sala, J. M. (dirs.), Tratado de Regulación del Sector Eléctrico, Aranzadi, Cizur Menor, 2009, pp. 49-87.
} 
consideración de factores como la garantía y la diversificación de suministros, potenciación de los recursos obtenidos en el territorio nacional y sustitución de las fuentes de energía que produzcan una mayor dependencia exterior ${ }^{6}$. La planificación energética presenta una serie de características propias ya que la prestación de los servicios energéticos está condicionada por la idoneidad de las infraestructuras que prestan soporte a esta actividad, infraestructuras que requieren un largo período desde que se identifica su necesidad hasta que se ponen en funcionamiento. De ahí que la antelación y la constante adaptación de las previsiones a la realidad cambiante se conviertan en herramienta imprescindible de la política energética a través de una correcta planificación ${ }^{7}$.

La Ley del Sector Eléctrico 54/1997, (LSE) dedica su artículo 4 a la planificación eléctrica. En él se señala que la planificación eléctrica, que tendrá carácter indicativo salvo en lo que se refiere a las instalaciones de transporte, será realizada por el Estado con la participación de las CCAA y sometida al Congreso de los Diputados.

Esta planificación deberá referirse, entre otros, a los siguientes aspectos que hacen necesario su sometimiento a evaluación ambiental:

a) Previsión de la demanda de energía eléctrica a lo largo del período contemplado.

b) Estimación de potencia mínima que debe ser instalada para cubrir la demanda prevista bajo criterios de seguridad del suministro, diversificación energética, mejora de la eficiencia y protección del medio ambiente.

c) Previsiones relativas a instalaciones de transporte y distribución de acuerdo con la previsión de la demanda energética.

El marco de regulación del sector eléctrico español, surgido de la LSE, tiene como fin básico el triple y tradicional objetivo de garantizar el suministro eléctrico, la calidad de dicho suministro y asegurar que se realice al menor coste posible, todo ello sin olvidar la protección del medioambiente, aspecto que adquiere especial relevancia dadas la incidencia de este sector sobre el medio.

\footnotetext{
${ }^{6}$ MARTÍN MATEO, R. Nuevo Derecho Energético, IEAL, Madrid, 1982, p.47.

${ }^{7}$ Así lo señala GUILLÉN CARAMÉS, J., en "Marco y régimen de las actividades del sector gasista en la Ley del Sector de Hidrocarburos", Muñoz Machado, S., Serrano González, M., Bacigalupo Sagesse, M. (dirs.), Derecho de la regulación económica. III. Sector energético, vol II, Iustel, Madrid, 2009, p. 1119.
} 
En términos similares, el artículo 4 de la Ley 34/1998, de Hidrocarburos (LSH) señala que la planificación en materia de hidrocarburos tendrá carácter indicativo, salvo en lo que se refiere a las instalaciones integrantes de la red básica de gas natural, a la red de transporte secundario, a la determinación de la capacidad de regasificación total de gas natural licuado necesaria para abastecer el sistema gasista, a las instalaciones de almacenamiento de reservas estratégicas de hidrocarburos líquidos y de almacenamiento básico de gas natural, a las instalaciones de transporte secundario y a la determinación de criterios generales para el establecimiento de instalaciones de suministro de productos petrolíferos al por menor, teniendo en estos casos carácter obligatorio para la garantía de suministro de hidrocarburos. ${ }^{8}$

\section{Competencia en materia de planificación energética}

La LSE en su artículo 3.1 establece que corresponde a la Administración General del Estado "Ejercer las facultades de planificación eléctrica en los términos establecidos en el artículo siguiente". La definición del suministro eléctrico (art. 2 LSE) como servicio universal y esencial legitima al Estado para intervenir y ordenar el sector energético garantizando la seguridad, continuidad, calidad y menor coste posible del suministro

\footnotetext{
${ }^{8}$ Dicha planificación deberá referirse a:
}

a) Previsión de la demanda de productos derivados del petróleo y de gas natural a lo largo del período contemplado.

b) Estimación de los abastecimientos de productos petrolíferos necesarios para cubrir la demanda prevista bajo criterios de calidad, seguridad del suministro, diversificación energética, mejora de la eficiencia y protección del medio ambiente.

c) Previsiones relativas a las instalaciones de transporte y almacenamiento de productos petrolíferos de acuerdo con la previsión de su demanda, con especial atención de las instalaciones de almacenamiento de reservas estratégicas.

d) Previsiones de desarrollo de la red básica de transporte de gas natural y de la capacidad de regasificación total de gas natural licuado necesaria para abastecer el sistema gasista, con el fin de atender la demanda con criterios de optimización de la infraestructura gasista en todo el territorio nacional.

e) Definición de las zonas de gasificación prioritaria, expansión de las redes y etapas de su ejecución, con el fin de asegurar un desarrollo homogéneo del sistema gasista en todo el territorio nacional.

f) Previsiones relativas a instalaciones de transporte y almacenamiento de combustibles gaseosos, así como de las plantas de recepción y regasificación de gas natural licuado, con el fin de garantizar la estabilidad del sistema gasista y la regularidad y continuidad de los suministros de gases combustibles.

g) Establecimiento de criterios generales para determinar un número mínimo de instalaciones de suministro de productos petrolíferos al por menor en función de la densidad, distribución y características de la población y, en su caso, la densidad de circulación de vehículos.

h) Los criterios de protección medioambiental que deben informar las actividades objeto de la presente Ley. 
eléctrico, de manera sostenible para el medio ambiente. De esta calificación deriva la competencia estatal de planificación energética. En cambio a pesar de que la LSH suprime en el sector del gas la consideración de servicio público, se ha mantenido para todas ellas la consideración de actividades de interés general y los suministros del sector de hidrocarburos tienen una especial importancia para el desenvolvimiento de la vida económica que supone que el Estado debe velar por su seguridad y continuidad y justifica las obligaciones de mantenimiento de existencias mínimas de seguridad que afectan a los productos petrolíferos y al gas.

La LSE atribuye la potestad de la planificación eléctrica al Estado con la participación de las CCAA, por tanto es una competencia del Estado. Es más el artículo 3.3 LSE no cita entre las competencias de las CCAA la de la planificación eléctrica. En esto se diferencia del artículo 3.3 LSH que sí parece reconocer competencia propia a las CCAA en materia de planificación al establecer que a las CCAA les corresponde la planificación, en coordinación con la realizada por el Gobierno. Esta contradicción realmente no es tal ya que la LSH en realidad no atribuye competencia planificadora propia a las CCAA sino de participación en la planificación estatal ${ }^{9}$.

La intervención de las CCAA en la planificación es mencionada y garantizada tanto por la LSH como por la LSE pero ninguna concreta en qué se plasma exactamente tal participación. A juicio de GONZÁLEZ ESPEJO, tal participación se traduce en la posibilidad que tienen las CCAA de ser oídas durante el proceso planificador, si bien sus alegaciones puedan no ser tenidas en absoluto en cuenta dado que la competencia corresponde al Consejo de Ministros y a la aprobación del Congreso. La participación de las CCAA en la planificación estatal se materializa por lo general en las alegaciones que realizan a la propuesta de planificación y su necesaria intervención en el seno de la EAE tal y como veremos.

La competencia del Estado en la planificación eléctrica es compartida con las CCAA pero, mientras en el régimen peninsular se requiere una mera participación de éstas, en el caso extrapeninsular se precisa que la planificación del Estado se realice de común acuerdo entre el Estado y las Ciudades y Comunidades Autónomas afectadas. La diferencia de matiz es importante ya que en este caso nos coloca ante una competencia

\footnotetext{
${ }^{9}$ Así lo interpreta GONZÁLEZ-ESPEJO GARCÍA, A., en López-Ibor Mayor, V., Beneyto Pérez, J. (dirs.), Comentarios a las Leyes Energéticas, Civitas, Madrid, 2006, p. 110.
} 
compartida $^{10}$. En este caso mientras que el artículo 4 señala que la planificación estatal se llevará a cabo con la participación de las CCAA, la DAd. 15 a sin cuestionar la competencia estatal, señala que tal planificación se realizará de acuerdo con las Comunidades Autónomas o Ciudades Autónomas afectadas.

Los nuevos Estatutos de Autonomía también hacen referencia a la competencia autonómica en materia de planificación energética ${ }^{11}$, así el Estatuto catalán en su artículo 133.3 señala en consonancia con lo señalado que "La Generalitat participa en la regulación y planificación de ámbito estatal del sector de la energía que afecte al territorio de Cataluña" y el Estatuto andaluz en idénticos términos en su artículo 49.4 establece que "La Junta de Andalucía participa en la regulación y planificación de ámbito estatal del sector de la energía que afecte al territorio de Andalucía a través de los órganos y procedimientos multilaterales a que se refiere el apartado 1 del artículo 221 de este Estatuto".

Por otro lado, debe destacarse la coexistencia de los planes estatales y los planes autonómicos. En este caso los planes autonómicos pueden establecer los objetivos a alcanzar, tanto estratégicos como operativos, determinando unas previsiones de consumo $\mathrm{y}$, en consecuencia, las previsiones de producción de energía eléctrica necesaria para cubrir la demanda y las instalaciones necesarias para ello. Nada obsta por tanto para que las CCAA en el ejercicio de sus competencias y en coordinación con lo establecido en el Plan estatal respectivo puedan aprobar sus propios planes energéticos como de hecho hacen $^{12}$.

Dentro del procedimiento de planificación energética estatal también debe considerarse la participación de la Comisión Nacional de Energía a la que corresponde participar mediante propuesta e informe en el proceso de planificación energética. Estamos ante una participación preceptiva pero no vinculante.

\footnotetext{
${ }^{10}$ SALMADOR SEGURA, J., en López-Ibor Mayor, Beneyto Pérez, Comentarios... cit., p. 1013.

${ }^{11}$ Sobre esta cuestión TORNOS MAS, J. "La distribución de competencias en el sector energético", Muñoz Machado, Serrano González, Bacigalupo Sagesse, Derecho de la regulación económica ... cit., p. 65 .

${ }^{12}$ Noticia sobre planes energéticos sometidos a EAE aprobados por las diferentes CCAA en el LÓPEZ RAMÓN, F. (coord.), Observatorio de Políticas Ambientales 2009, Aranzadi, Cizur Menor, 2009, y también en los anteriores.
} 


\section{Objetivos de la planificación energética: el objetivo ambiental}

Los objetivos de la planificación energética a día de hoy no son otros que la reducción de costes, el ahorro y la eficiencia, la garantía del suministro, la diversidad de las fuentes y, por supuesto en nuestros días, el fomento de las energías renovables.

La planificación pública del sector energético, y en particular del sector eléctrico, así lo afirma DE LA CRUZ FERRER 13 , constituye un elemento necesario para "1) asegurar la disponibilidad de infraestructuras de generación, transporte y distribución que garanticen la seguridad del suministro, 2) ofrecer al sector empresarial mediante las técnicas adecuadas de prospectiva y planificación, la información relevante sobre la evolución del sector y sus condicionantes y sus necesidades, de forma que pueda ejercer su libre iniciativa, 3) permitir la coordinación entre las diferentes políticas públicas en materia de energía, ordenación del territorio y urbanismo, protección del medio ambiente y transporte, y 4) mantener y mejorar el sistema eléctrico, mediante una vertebración racional de las redes que permita coordinar la realización de las distintas actividades destinadas al suministro."

Como señala DOMINGO LÓPEZ, la Administración en su actividad planificadora energética, se enfrenta a innumerables variables económicas, tecnológicas, de política comunitaria, sociológicas ${ }^{14} \mathrm{y}$, por supuesto habría que añadir las ambientales. Es por ello que la planificación energética debe introducir la variable ambiental y de ahí su exigencia de sometimiento a evaluación ambiental.

\section{Clases de planificación energética: vinculante e indicativa}

\subsection{Antecedentes.}

Antes de hacer referencia a la planificación indicativa y vinculante, es necesario hacer una breve exposición de la evolución histórica de la planificación energética en España para entender la realidad actual. En un principio, en los años 50 y 60, era la propia patronal eléctrica la que llevaba a cabo su propia planificación autovinculante. Las crisis energéticas posteriores de los 70 llevaron a una planificación energética centralizada,

\footnotetext{
${ }^{13}$ DE LA CRUZ FERRER, J. "El funcionamiento del sistema eléctrico. Sujetos. Separación de actividades. Planificación", Muñoz Machado, Serrano González, Bacigalupo Sagesse, Derecho de la regulación económica ... cit., p. 295.

${ }^{14}$ DOMINGO LÓPEZ, E., Régimen jurídico de las energías renovables y la cogeneración eléctrica, MAP, Madrid, 2000, p.140.
} 
estatal, exhaustiva y vinculante en todos los ámbitos. Ello tenía el inconveniente para los operadores de no poder realizar otras inversiones que las contempladas en el Plan pero la contrapartida de que las empresas que cumplieran los dictados del Plan verían garantizadas la recuperación de sus inversiones. Es decir, el Estado asumía las decisiones y la empresa las inversiones, como es lógico quien invertía no asumía el riesgo, sino el que había decidido, por lo que se garantizaban de esta manera las inversiones ${ }^{15}$. Realmente quien asumía el riesgo era el consumidor al que se acababa trasladando los $\operatorname{costes}^{16}$. Y es que uno de los riesgos de la planificación estatal vinculante era la situación generalizada de sobrecapacidad en generación incrementando los costes en generación y por consiguiente el precio de la electricidad. El sistema eléctrico español ha estado siempre basado en una estructura empresarial privada pero con una tremenda intervención pública a través de la planificación. El Estado planificaba y las empresas invertían con el fin de garantizar el abastecimiento a largo plazo, ahora bien, la responsabilidad recaía sobre la Administración cuya elección sobre la composición y dimensión de las fuentes de generación respondía a opciones de pura política energética. En estas circunstancias, los errores fueron más que los aciertos llevando a una sobrecapacidad de instalación que ha permanecido durante muchos años ${ }^{17}$.

Frente a la concepción tradicional de planificación unilateral basada en previsiones de la autoridad, la nueva planificación sectorial prevista en las actuales leyes energéticas, pretende principalmente orientar la actividad privada en sectores como el energético en el que es necesario facilitar a los inversores una orientación informativo-estratégica en un sector como éste que exige inversiones con maduración a largo plazo ${ }^{18}$, es decir, las inversiones en infraestructuras energéticas requieren mucho tiempo de maduración y la seguridad del suministro está condicionada a la idoneidad de tales infraestructuras que le dan soporte ${ }^{19}$.

\footnotetext{
${ }^{15}$ Todo este proceso de la planificación energética en España, y en particular la eléctrica son resumidos extraordinariamente en ARIÑO ORTIZ, G., Principios de Derecho Público Económico, Comares, Granada, 1999, pp. 334-341.

${ }^{16}$ Es el caso de la moratoria nuclear establecida en el PEN 1983 por el que la paralización de las centrales nucleares en construcción con importantes inversiones ya realizadas, acabo siendo asumido por la tarifa eléctrica de todos los ciudadanos.

${ }^{17}$ FABRA UTRAY, J., ¿Liberalización o regulación? Un mercado para la electricidad, Marcial Pons, Madrid, 2004, p. 99.

${ }^{18}$ Cfr. ARIÑO ORTIZ, G., Principios de Derecho Público Económico, Comares, Granada, 1999, p.323.

${ }^{19}$ CAlancha MARZANA, F., en VVAA, Manual del Sector de Hidrocarburos, Aranzadi, Cizur Menor, 2008, p.72.
} 
Como señala la propia exposición de motivos de la LSE "La planificación estatal, por último, queda restringida a las instalaciones de transporte, buscando así su imbricación en la planificación urbanística y en la ordenación del territorio. Se abandona la idea de una planificación determinante de las decisiones de inversión de las empresas eléctricas, que es sustituida por una planificación indicativa de los parámetros bajo los que cabe esperar que se desenvuelva el sector eléctrico en un futuro próximo, lo que puede facilitar decisiones de inversión de los diferentes agentes económicos.”. Se establece un modelo de liberalización energética sobre la base de unas infraestructuras de redes, respecto de las que los terceros tienen un derecho de acceso regulado. No obstante, al mismo tiempo se establece la necesaria planificación pública con el fin de que los poderes públicos puedan orientar y fijar las premisas básicas de tal funcionamiento, es decir, con la planificación, los poderes públicos diseñan el escenario sobre el que los agentes interpretan el papel ${ }^{20}$. La actual planificación energética es un ejemplo de que los mecanismos de planificación pueden y deben hacerse compatibles con el mercado y la libertad.

Tanto la LSE como la LSH repiten el mismo esquema en cuanto a la planificación. En ambas se consideran las estructuras de redes como instalaciones sujetas a planificación vinculante de carácter obligatorio, siendo esta planificación en el resto de actividades como la generación, meramente indicativa.

Como señala GONZÁLEZ ESPEJO, en ambas leyes apenas se dedica importancia a la planificación fijando unas pautas mínimas y estableciendo como fin de la misma la garantía del suministro pero tratando de interferir lo menos posible en la actividad de los operadores y estableciendo sobre ellos una mera orientación ${ }^{21}$. En definitiva, como afirma ARIÑO ORTIZ, la garantía del suministro energético aconseja contar con mecanismos de planificación estratégica e informativa pero sin eliminar la iniciativa y la responsabilidad empresarial ${ }^{22}$.

Igualmente, la liberalización del sector de los hidrocarburos implica que la totalidad de actividades petroleras se desarrollan en un mercado no intervenido, y en el sector del

\footnotetext{
${ }^{20}$ Símil empleado por GONZÁLEZ-ESPEJO GARCÍA, A., en López-Ibor Mayor, Beneyto Pérez, Comentarios... cit., p. 107.

${ }^{21}$ GONZÁLEZ ESPEJO, A., "Cuestiones jurídicas asociadas a la planificación energética”, La nueva regulación eléctrica. VII Jornadas jurídicas del sector eléctrico, Civitas, Madrid, 2002, p.37.

${ }^{22}$ Cfr. ARIÑO ORTIZ, G., Principios de Derecho Público Económico, Comares, Granada, 1999, p. 343.
} 
gas $^{23}$, las de prospección o extracción y comercialización no sean actividades reguladas. Es por ello que la planificación en el sector de los hidrocarburos sea una planificación indicativa.

Tanto la LSE como la LSH distinguen entre actividades sometidas a planificación indicativa y actividades sometidas a planificación vinculante.

\subsection{La planificación energética vinculante}

La planificación obligatoria se refiere a las grandes infraestructuras de transporte sobre las que descansa el sistema energético y que permiten su vertebración. Ejemplo reciente de planificación vinculante lo constituye el Plan de los sectores del gas y electricidad 2008-2016 que contempla una serie de infraestructuras que necesariamente deberán acometerse en materia de instalaciones de transporte de energía eléctrica y gasoductos.

Forman parte de la planificación obligatoria las siguientes infraestructuras: Red de transporte de energía eléctrica ${ }^{24}$, Red básica de gasoductos, Red de gasoductos secundarios $^{25}$, Instalaciones de regasificación de gas natural licuado necesarias para

\footnotetext{
${ }^{23}$ Sobre la planificación en el sector gasista y su evolución véase, DEL GUAYO CASTIELLA, I., El servicio público del gas. Producción, transporte y suministro. Marcial Pons, Madrid, 1992.; SÁNCHEZ GUTIÉRREZ, M.M., La regulación del sector del gas natural, Tirant lo Blanch, Valencia, 2006.

${ }^{24}$ En concreto el plan 2008-2016 prevé las siguientes infraestructuras: Refuerzos estructurales en la red de $400 \mathrm{kV}$; Desarrollo de la red de $220 \mathrm{kV}$ que incrementa la seguridad y garantía del suministro; Refuerzo de las conexiones internacionales con Portugal mediante dos nuevos ejes de $400 \mathrm{kV}$ uno al norte y otro al sur, y con Francia a través de un nuevo eje de $400 \mathrm{kV}$ a través del Pirineo Central.; Alimentación de nuevos ejes ferroviarios del TAV desde la red de transporte de 400 y $220 \mathrm{kV}$ previstos por el Administrador de Infraestructuras Ferroviarias; Desarrollo de las redes de 400 y $220 \mathrm{kV}$ que faciliten la integración de las energías renovables ; Incremento del número de unidades de transformación 400/220 $\mathrm{kV}$ y 400/132-110 kV, repartidas por toda la península, que mejoran e incrementan el apoyo entre las redes de transporte y entre la red de transporte y la de distribución; Alimentación de las desaladoras de la costa mediterránea, desarrolladas bajo el programa AGUA del Ministerio de Medio Ambiente bien de forma directa o mediante apoyo a la distribución que las suministre; Desarrollo de interconexiones internacionales.

${ }^{25}$ En materia de infraestructuras de transporte de gas, el mismo Plan prevé las siguientes infraestructuras: El nuevo Eje de Galicia a Madrid, compuesto por los gasoductos Guitiriz-Lugo, Lugo-Villafranca del Bierzo, Villafranca del Bierzo-Castropodame, Castropodame-Zamora y Zamora-Algete junto con las ampliaciones de las estaciones de compresión de Zamora y Algete; La continuación de la duplicación del Eje del Ebro hasta Villar de Arnedo junto con la ampliación de la estación de compresión de Zaragoza; El gasoducto Huelva-Almendralejo servirá para completar la Ruta de la Plata como un eje de transporte que unirá la planta de regasificación de Huelva y la de El Musel en Asturias; La duplicación de los gasoductos Algete-Burgos y Burgos-Haro. El primero se configura como la continuación natural de las infraestructuras de transporte Llanera-Villapresente-Burgos y el segundo reforzará la alimentación del centro de la península desde las entradas de Bilbao y Larrau.
} 
abastecer el sistema, Instalaciones de almacenamiento de reservas estratégicas de hidrocarburos líquidos y de almacenamiento básico de gas natural.

Como es sabido, el transporte de energía, la concreción y definición de sus instalaciones se realiza, con carácter vinculante, mediante la planificación estatal. En el caso de la planificación vinculante, el plan establece con carácter obligatorio y vinculante las diferentes alternativas. Ahora bien, imaginemos que una infraestructura de transporte de energía prevista en la correspondiente planificación que ha sido sometida a EAE, con posterioridad pueda tener problemas en su autorización por cuestiones ambientales relacionadas con la EIA de la concreta red de transporte. Desde luego la solución no será fácil. El desarrollo de las infraestructuras incluidas en la planificación energética supone la realización de actuaciones con efectos ambientales significativos sobre el medio ambiente, positivos y negativos, y de otras actuaciones que por su naturaleza no suponen afección alguna al medio y que se consideran no significativas.

Como se señala en la reciente planificación energética 2008-1016, las instalaciones que tienen una mayor afección sobre el medio ambiente son precisamente las sujetas a planificación vinculante. Así en el sector eléctrico lo son las nuevas líneas eléctricas aéreas de transporte de energía eléctrica, nuevos cables subterráneos de transporte y nuevas subestaciones eléctricas y en el sector de los hidrocarburos y en concreto del gas destacan desde el punto de vista de su posible afección sobre el medio ambiente la construcción de gasoductos, plantas de regasificación, estaciones de compresión y los almacenamientos subterráneos.

\subsection{La planificación energética indicativa}

Se mantiene la planificación vinculante estatal para las infraestructuras de transporte mientras que, como se ha dicho, se abandona este concepto para las decisiones de inversión en generación, donde se sustituye "por una planificación indicativa de los parámetros bajo los que cabe esperar que se desenvuelva el sector eléctrico en un futuro próximo, lo que puede facilitar decisiones de inversión de los diferentes agentes económicos”. La actividad de distribución no está sometida a planificación vinculante.

Como venimos señalando, la reciente y vigente de planificación energética de los sectores de electricidad y gas 2008-2016, también introduce previsiones sobre el comportamiento futuro de la demanda, los recursos necesarios para satisfacerla, la 
evolución de las condiciones del mercado para garantizar el suministro y los criterios de protección ambiental. $^{26}$

La planificación indicativa aporta los parámetros bajo los que cabe esperar que se desenvuelvan estos sectores, promoviendo y facilitando aquellas decisiones de inversión de los diferentes agentes económicos y estableciendo líneas de actuación y criterios generales. Así, aunque no se trata de una planificación vinculante, sí aporta previsiones sobre el comportamiento de la demanda, los recursos necesarios para satisfacerla, la necesidad de nueva potencia de generación, la evolución de las condiciones de mercado para la consecución de la garantía de suministro y los criterios de protección ambiental.

La articulación de los elementos que configuran la planificación indicativa en materia energética tiene como fin el equilibrio entre la competitividad, la seguridad de aprovisionamiento y la protección del medio ambiente ${ }^{27}$.

Sobre la planificación indicativa y el marco regulatorio es necesario señalar que los agentes económicos, las empresas energéticas no son las que marcan la política energética, las empresas hacen las inversiones que la política y planificación energética del Gobierno de turno proponga. Así y en función del momento histórico y de las diferentes planificaciones se ha promovido más la construcción de centrales hidráulicas, nucleares o térmicas de ciclo combinado. Evidentemente ahora la apuesta es por las energías renovables. Ahora bien, la planificación indicativa, no por serlo deja de ser un instrumento de intervención administrativa dado que su esencial valor radica en el impulso programático que supone y que puede determinar criterios de regulación ${ }^{28}$.

La planificación indicativa no puede limitar la libertad en cuanto a la instalación de centrales generadoras ni limitar la entrada en el mercado a ninguna instalación por

\footnotetext{
${ }^{26}$ Así, las proyecciones del documento de planificación establecen que el consumo de energía primaria en España crecerá a una tasa media anual del 1,4\% entre 2006 y 2016, alcanzando un total de 165 Millones de Toneladas Equivalentes de Petróleo (Mtep) en el último año del periodo. Esta tasa de crecimiento de la energía primaria es inferior a la de la energía final, 1,6\%, debido al mayor rendimiento de la estructura de generación eléctrica prevista.

Se espera una reducción del 1,6\% anual medio en la intensidad energética primaria en España (consumo de energía primaria/PIB) en el periodo de previsión, alcanzando niveles muy inferiores a los de 1990. Esta evolución supone un importante cambio de tendencia desde el crecimiento continuo habido entre 1990 y 2004, continuando con la reducción registrada en 2005 y especialmente en 2006 y 2007.

${ }^{27}$ GUILLÉN CARAMÉS, J., "Marco y régimen de las actividades del sector gasista en la Ley del Sector de Hidrocarburos" en Muñoz Machado, Serrano González, Bacigalupo Sagesse, Derecho de la regulación económica... cit., p. 1124.

${ }^{28}$ CALANCHA MARZANA, F., en VVAA, Manual del Sector de Hidrocarburos cit., p. 73.
} 
razones de política energética o determinaciones de la planificación. No obstante, la instalación de plantas de generación está sujeta a la previa autorización administrativa sustantiva y ambiental ${ }^{29}$ (autorización ambiental integrada por lo general) y si bien tal otorgamiento dependerá de criterios objetivos y reglamentados como son los relativos a la seguridad de las instalaciones, la protección del medio ambiente o la ordenación del territorio, es más que posible que también se tengan en consideración los objetivos, el mix ideal y otros factores previstos en la respectiva planificación energética indicativa. Muestra de ello lo constituye la Orden ministerial ITC/1785/2009, de 3 de julio, por la que se acuerda como fecha de cese definitivo de la explotación de la Central nuclear de Santa María de Garoña el día 6 de julio de 2013, y se autoriza su explotación hasta dicha fecha. Entre otros motivos que se esgrimen para fundamentar la citada Orden tiene un peso importante la apuesta del Gobierno por el desarrollo de las energías renovables, una apuesta elogiable pero que a juicio de la empresa no es fundamento suficiente para justificar el cierre de una instalación que cumple con todas las exigencias de seguridad según el organismo regulador (CSN) y de hecho es uno de los motivos en los que fundamenta el reciente recurso interpuesto contra la citada Orden ante la sala de lo contencioso-administrativo de la Audiencia Nacional.

Ahora bien, la planificación indicativa puede no serlo tanto al estar también determinada por la planificación vinculante, así por ejemplo, las infraestructuras previstas en la planificación de los sectores de electricidad y gas 2008-2016, se constituye como instrumento herramienta a través de la cual, la Administración puede incidir en el fomento de la generación eléctrica mediante tecnologías limpias y así lo hace dando prioridad a la instalación de las líneas de evacuación de energía eléctrica procedente de fuentes de energías renovables y a la construcción de gasoductos que den cobertura a la demanda de gas, tanto para cogeneración como para ciclos combinados con gas natural.

DOMINGO LÓPEZ denomina la planificación indicativa como informativa y junto a la planificación vinculante cita la planificación que él califica de influyente. La planificación influyente carece de efectos jurídicos vinculantes pero pretende influir en la actividad económica privada estableciendo determinados objetivos (fomento de las

\footnotetext{
${ }^{29}$ Sobre estas cuestiones me he ocupado en "El caso de las centrales térmicas de ciclo combinado ubicadas en el municipio de Castejón (Navarra): implicaciones jurídico-ambientales" en LOPERENA ROTA, D. (dir.), Conflicto Ambiental, Aranzadi, Cizur Menor, 2009, pp. 55-104.
} 
energías renovables, ahorro energético) estableciendo medios para la consecución de objetivos de carácter incentivador, sea el caso de incentivos, subvenciones o exenciones fiscales. Con arreglo a esta interpretación, la planificación indicativa supone que en un marco de libertad de establecimiento el Estado oriente las decisiones del mercado libremente adoptadas con el fin de garantizar el suministro, fomentando si es necesaria tal iniciativa privada en la dirección establecida por el respectivo plan ${ }^{30}$.

\section{Aspectos formales de la planificación energética: procedimiento, carácter normativo e Impugnabilidad.}

\subsection{Antecedentes}

Históricamente los planes energéticos han sido aprobados a través de órdenes ministeriales o acuerdos del Gobierno comunicados al Congreso. En la actualidad, aunque ni la LSE ni la LSH establecen procedimiento alguno de planificación, no obstante nuestro Estado de Derecho exige que toda actuación administrativa esté procedimentalizada e incluso actuaciones como la planificación energética que entra en buena medida dentro del ámbito de las decisiones estrictamente políticas, debe culminar con un acto formal que adquiera forma exterior, ya se reglamentaria o de simple acuerdo. En materia de transporte de energía, los artículos 8 y siguientes del RD 1955/2000, establecen el procedimiento de elaboración y aprobación del documento de planificación con una vigencia de cinco años y que es aprobada por el Consejo de Ministros, aunque también sometida a la Comisión de Industria del Congreso de los Diputados. En su artículo 31.3 establece que será aprobado mediante Acuerdo.

Así como la planificación eléctrica tiene un procedimiento regulado en el RD 1955/2000 en lo que se refiere a las infraestructuras de transporte ${ }^{31}$, la legislación de hidrocarburos no prevé procedimiento alguno en cuanto a tal planificación se refiere. Sobre este punto el Dictamen de la Abogacía del Estado del Ministerio de Industria, Comercio y Turismo (núm. Exp. 246/2007) referido al procedimiento de actualización anual y publicidad de las infraestructuras de transporte de energía eléctrica aplicable a la planificación de la red básica de gas natural, señala que "Es claro que no existiendo regulación específica para

\footnotetext{
${ }^{30}$ GONZÁLEZ ESPEJO, “Cuestiones jurídicas...” cit., p. 26.

${ }^{31}$ Procedimiento con su inicio, sujetos, audiencia, aprobación que es analizado por GONZÁLEZ ESPEJO, “Cuestiones jurídicas...” cit., pp. 48-55.
} 
el procedimiento de planificación de la red básica de gas natural, ha de seguirse el correspondiente a la red de transporte de energía eléctrica”,32.

\subsection{Procedimiento de aprobación y carácter normativo}

En la planificación energética española, la forma adoptada para su adopción ha sido tradicionalmente distinta a la ley ${ }^{33} \mathrm{u}$ otra norma de eficacia jurídica obligatoria a diferencia de otras planificaciones ${ }^{34}$.

El procedimiento seguido en España para la aprobación de los diferentes Planes Energéticos Nacionales ha sido el previsto en el artículo 198 del Reglamento del Congreso. Según este precepto el Gobierno aprueba el Plan y lo somete a debate en Comisión, formulándose las correspondientes propuestas de resolución que serán sometidas a la aprobación final del Pleno. Se trata de un breve procedimiento de estudio, planteamiento de propuestas de resolución y debate en comisión parlamentaria o excepcionalmente en Pleno, que concluye mediante la aprobación de una o varias resoluciones que son publicadas en el Boletín Oficial de las Cortes Generales.

De la forma que adopte el citado Plan va a deducirse en buena medida su carácter normativo o no y en cierto modo su vinculatoriedad. Algunos autores sostienen que se trata de una decisión de carácter meramente político, carente de toda fuerza jurídica obligatoria y que por tanto carece de la consideración de norma jurídica ya que no se publica en el Boletín Oficial. El modo en que se aprueba no es el propio de una ley, ni el procedimiento común de aprobación de un reglamento, de lo que cabría deducir que carece de eficacia jurídica vinculante propia del carácter normativo ${ }^{35}$. A mi juicio no cabe duda del carácter de norma jurídica vinculante caso de que un plan en cuestión se apruebe mediante ley o norma reglamentaria publicada como es preceptivo en el respectivo

\footnotetext{
${ }^{32}$ Este dictamen y su comentario puede consultarse en SOLER TAPPA, E., Derecho de la Energía. Dictámenes de la Abogacía del Estado en el Ministerio de Industria, Vol. I, Civitas, Madrid, 2008, pp. 445-450.

${ }^{33}$ Caso de la planificación hidrológica estatal aprobada mediante Ley y los planes hidrológicos de cuenca aprobados mediante Real Decreto, sobre la planificación hidrológica, características y relación con otros planes, por todos, PALLARĖS SERRANO, A., La planificación hidrológica de cuenca como instrumento de ordenación ambiental sobre el territorio, Tirant lo Blanch, Valencia, 2007.

${ }^{34}$ DOMINGO LÓPEZ, E., Régimen jurídico de las energías renovables y cogeneración eléctrica, MAP, Madrid, 2000, p. 132.

${ }^{35}$ Así ya lo señalaba MARTÍN MATEO, R. Nuevo Derecho Energético, Madrid, 1982, p. 56. Más recientemente, GONZÁLEZ-ESPEJO GARCÍA, A., en López-Ibor Mayor, Beneyto Pérez, Comentarios ... cit., p. 112.
} 
boletín oficial, que contenga objetivos claros y precisos de los que puedan derivarse obligaciones. En tal supuesto vincula tanto a la Administración autora del plan como a sus eventuales destinatarios.

Es cierto que la planificación energética no tiene naturaleza normativa, legal o reglamentaria como ocurre con otros planes (planes hidrológicos, planes urbanísticos), en definitiva, carece de eficacia jurídica obligatoria, aunque esto es a mi juicio sólo predicable de la planificación indicativa, no así de la planificación vinculante. En la planificación vinculante los planes energéticos sí tienen naturaleza normativa reglamentaria tal y como sostiene DÍAZ LEMA al afirmar que la planificación energética aprobada así se trata de "una norma reglamentaria con un procedimiento especial de elaboración, procedimiento que no le quita el carácter de regla jurídica unilateral y obligatoria" ${ }^{\prime 36}$. Y es que si se establecen una serie de criterios de obligado cumplimiento por la planificación vinculante evidentemente deben ser cumplidos, de ahí su efícacia normativa obligatoria. Es más, en los supuestos en los que de la planificación se deriven obligaciones para el propio planificador es claro que ésta tendrá un carácter vinculante en lo que se ha venido a llamar como autovinculación de la Administración a sus propios planes, dado que de lo contrario, cabe preguntarse de qué servirían.

Para otros autores, estamos ante un tipo de normación informal o difusa susceptible de despegar consecuencias jurídicas ${ }^{37}$. Según TRILLO-FIGUEROA y LÓPEZ-JURADO, los planes energéticos tendrían una doble vertiente: por un lado inducen el gasto público al prever la demanda de electricidad y definir los medios necesarios para su cobertura y por otro, de manera más importante, el plan induce y determina las conductas de los sujetos privados que operan en el sector. De esta segunda vertiente se deduce, a pesar de su mero carácter indicativo, que la revisión del Plan conllevaría el surgimiento del derecho a indemnización por parte de los sujetos que padecieran daños y perjuicios derivados de la citada revisión. Esto es consecuencia de la vinculación práctica de los agentes que operan en el sector, dicha vinculación es real y efectiva sin que quepa adoptar decisiones relevantes al margen de la planificación ${ }^{38}$.

\footnotetext{
${ }^{36}$ DÍAZ LEMA, J.M. "Sector energético: política y derecho", Serie Ensayos-6, Mallorca, 1984, p.59.

${ }^{37}$ TRILLO-FIGUEROA, J., LÓPEZ-JURADO ESCRIBANO, F.B., La regulación del sector eléctrico, Civitas, Madrid, 1996, p. 241.

${ }^{38} \mathrm{Ibid}$.
} 
Y es que los planes energéticos condicionan las inversiones en instalaciones eléctricas de producción, ya que en ellos se contiene además de la previsión de la demanda, la selección de opciones de oferta. Las determinaciones que hacen los planes energéticos sobre instalaciones energéticas de generación inciden, condicionan y, en buena medida, sustituyen las decisiones económicas de las empresas que operan en el sector ${ }^{39}$.

Como ya señaló S. MARTÍN-RETORTILLO, la regla en los planes económicos en los sistemas de economía de mercado es su carácter vinculante para el sector público y simplemente indicativo para el privado ${ }^{40}$. Los servicios energéticos constituyen una parte muy importante de la actividad económica $\mathrm{y}$, sobre todo, suponen servicios imprescindibles y con un valor estratégico fundamental en cualquier economía ya sea de mercado o no.

\subsection{Impugnabilidad}

Como hemos visto, la planificación tiene su relevancia constitucional, en algunos casos carácter normativo y en más de una ocasión se ha planteado su posible revisión jurisdiccional. De su carácter normativo o no puede derivar el que sean o no impugnables los citados planes. Estamos ante un plan aprobado por el Gobierno que cuenta con el respaldo de la Cámara Baja, de ahí que difícilmente pueda ser recurrible en cuanto a sus determinaciones y contenidos ${ }^{41}$, y es que otra de las características de la planificación es la de ser una actividad discrecional de la Administración ya que, respetándose escrupulosamente el procedimiento establecido, la Administración puede optar libremente por una opción entre varias, siempre y cuando ésta no sea contraria a la legalidad vigente.

Obviamente cabrá recurso en caso de que no se hubieren respetados las prescripciones normativas procedimentales, como la omisión de la preceptiva evaluación ambiental estratégica o de la necesaria participación de alguna Comunidad Autónoma o la falta de informe de la CNE. En lo que concierne al aspecto ambiental debe destacarse que la evaluación ambiental debe calificarse como un trámite esencial dentro del procedimiento aprobatorio del plan o programa, por lo que su ausencia determinaría la nulidad del plan o

\footnotetext{
${ }^{39}$ Op. cit., p. 243.

${ }^{40}$ MARTín RETORTILlO, S., Derecho Administrativo Económico, tomo I, Madrid, 1988, p.330.

${ }^{41}$ GONZÁlEZ-ESPEJO GARCÍA, A., en López-Ibor Mayor, Beneyto Pérez, Comentarios... cit., p. 113.
} 
programa. A esta conclusión se llega aunque el resultado de la EAE no tenga carácter vinculante pero al sí ser preceptivo y determinante su omisión constituiría un supuesto claro del 62.1e) LRJPAC que determina la nulidad de pleno derecho de los actos dictados prescindiendo total y absolutamente del procedimiento legalmente establecido. En este caso tal nulidad se podría hacer valer por la vía de la revisión de oficio (102 LRJPAC) o bien a través de la impugnación del acto definitivo de aprobación del plan ${ }^{42}$.

Como se ha señalado, los planes energéticos en la actualidad son aprobados mediante Acuerdo del Consejo de ministros. Estos acuerdos como otros, son plenamente fiscalizables ante la jurisdicción contencioso-administrativa de acuerdo con la LJCA. Ahora bien, cabe preguntarse qué puede ser fiscalizado en vía de recurso judicial contencioso-administrativo respecto de un acto del Consejo de ministros en materia de planificación energética. El contenido discrecional no parece que pueda ser fiscalizable salvo que sea contrario a la legislación vigente del sector, sí todos los elementos reglados tales como procedimiento.

Otra cuestión es que de la planificación adoptada se pueda inducir la vulneración de derechos subjetivos ya sean patrimoniales o ya sean ambientales. En el caso de la planificación indicativa no parece que pudiera invocarse pero sí quizá en el caso de la obligatoria $^{43}$, pero surge la pregunta de qué derechos subjetivos vulnera un plan vinculante.

Una cuestión más relacionada con la eventual impugnación de un plan ya sea por su contenido o por la omisión del procedimiento legalmente establecido para su aprobación es la solicitud de su suspensión como medida cautelar en tanto no se resuelva el correspondiente recurso. En este sentido habrá que estar a lo establecido en los artículos 129 y siguientes LJCA 29/1998 en vía judicial. No es una cuestión disparatada habida cuenta de que la Ley 2/2002 de la Comunidad de Madrid prevé expresamente la suspensión de los planes que hayan sido aprobados sin someterse a evaluación ambiental cuando ésta fuese preceptiva.

\subsection{Impugnación por falta de cumplimiento de las previsiones establecidas en un plan}

\footnotetext{
${ }^{42}$ Cfr. LOZANO CUTANDA, Derecho Administrativo Ambiental cit., p. 349, quien cita como ejemplo en el ámbito de la EIA, la STS de 29 de octubre de 2002, la omisión de la evaluación conlleva como trámite esencial, la nulidad del proyecto.

${ }^{43}$ Así lo sostiene GONZÁLEZ ESPEJO, en "Cuestiones jurídicas...” cit., p. 53.
} 
Cuestión diferente es la referida a los supuestos en los que lo que se pretende impugnar es no ya el propio plan, sino la falta de cumplimiento de las previsiones establecidas en el mismo una vez aprobado. Evidentemente, si afirmamos el carácter normativo o reglamentario de los planes energéticos sometidos a EAE la consecuencia ulterior será el de su obligatoriedad en el cumplimiento de las previsiones que el propio Plan prevea como vinculantes.

A juicio de DELGADO IRIBARREN, dado que los planes carecen de naturaleza normativa, no cabe alegar ante un órgano jurisdiccional el incumplimiento de un plan que estará sujeto a tutela política pero no judicial ${ }^{44}$. En el mismo sentido, MARTÍN MATEO considera dudoso que dado el aspecto no normativo de los planes pueda exigirse por parte de los particulares ante la eventual alteración unilateral por parte del Gobierno de sus objetivos y directrices, o la negativa a cumplir sus compromisos frente a sujetos que deciden acogerse al Plan y solicitar los beneficios previstos ${ }^{45}$. Ahondando en este debate, SALAS HERNÁNDEZ señala que sólo la aprobación de un plan con carácter normativo, legislativo incluso, podría hacer de obligado cumplimiento las previsiones del mismo tanto para las Administraciones Públicas como para las empresas que actúan en el sector energético $^{46}$.

\section{LA PLANIFICACIÓN ENERGÉTICA COMO CAPÍTULO DESTACADO EN EL PROYECTO DE LEY DE ECONOMÍA SOSTENIBLE.}

El recientemente aprobado proyecto de ley de economía sostenible ${ }^{47}$ aún pendiente de discusión parlamentaria, como es bien sabido dedica una importancia preponderante a la energía y a los aspectos ambientales relacionados con ella, como la reducción de emisiones de gases de efecto invernadero, partiendo para ello de la necesaria planificación.

Con tal fin, el proyecto introduce un buen número de preceptos dedicados a la planificación energética. Como ha señalado el propio Gobierno estatal, este proyecto de

\footnotetext{
${ }^{44}$ DELGADO-IRIBARREN GARCÍA-CAMPERO, M., "El Plan Energético Nacional (PEN) 1983”, RAP, núm. 104, 1984, p. 453.

${ }^{45}$ MARTIN MATEO, Nuevo Derecho Energético cit., p.54.

${ }^{46}$ SALAS HERNÁNDEZ, J., "La Energía", en Martín Retortillo, S. (dir.), Derecho Administrativo Económico II, La Ley, Madrid, 1991, p. 924.

${ }^{47}$ Aprobado por el Consejo de Ministros de 19 de marzo de 2010.
} 
ley trata de impulsar la sostenibilidad del modelo energético. Se recogen los grandes principios aplicables en la materia, esto es, la garantía de la seguridad del suministro, la eficiencia económica y el respeto al medio ambiente, y se fija el objetivo nacional de una reducción de un 20 por 100 de las emisiones de gases de efecto invernadero y de un consumo del 20 por 100 de energías renovables sobre el total de consumo de energía bruto, para el año 2020 .

El artículo 98 bajo el título de "Planificación energética indicativa: generación", establece que el Gobierno, en el plazo de tres meses desde la entrada en vigor de esta Ley, previo informe de la Conferencia Sectorial de Energía y tras el correspondiente proceso de información pública, aprobará un documento de planificación, que recogerá con carácter indicativo varios escenarios sobre la evolución futura de la demanda energética, sobre los recursos necesarios para satisfacerla, sobre las necesidades de nueva potencia y, en general, previsiones útiles para la toma de decisiones de inversión por la iniciativa privada y para las decisiones de política energética, fomentando un adecuado equilibrio entre la eficiencia del sistema, la seguridad de suministro y la protección del medio ambiente.

Entrando en aspectos de objetivos puramente ambientales relacionados con la citada planificación el proyecto de ley señala que se orientará a la consecución, bajo diferentes escenarios de demanda, de los siguientes objetivos para el año 2020:

a) Maximizar la participación de las energías renovables en la cesta de generación energética $y$, en particular en la eléctrica. Un pilar básico de la estrategia medioambiental en el ámbito de la energía es el apoyo al desarrollo de las energías renovables. La apuesta por esta fuente de energía se basa, en primer término, en su reducido impacto ambiental en comparación con otras energías, y en su carácter de recurso autóctono, que favorece, por tanto, el autoabastecimiento energético y la menor dependencia del exterior. Pero se justifica sobre todo por su contribución al desarrollo sostenible, que constituye uno de los objetivos básicos de la política española a largo plazo.

b) Consecuentemente, reducir la participación de las energías con mayor potencial de emisiones de $\mathrm{CO} 2$ en la cesta de generación energética y, en particular, en la eléctrica

c) Mantener, de conformidad con la normativa vigente, el calendario de cumplimiento de los 40 años de vida útil de las centrales del parque nuclear existentes, de acuerdo con su 
vida de diseño, incorporando en todo caso a dicha normativa el cumplimiento de requerimientos medioambientales y de seguridad específicos en los casos de renovación extraordinaria de las concesiones por encima de dicho plazo, derivadas del desarrollo de nuevas tecnologías de su necesidad de garantizar el mantenimiento del suministro.

En lo que se refiere a la planificación energética vinculante, el proyecto de ley en su artículo 99 señala que en la planificación vinculante establecida tanto en la LSE como en la LSH deben ser observados criterios que contribuyan a desarrollar un sistema energético seguro, eficiente y respetuoso con el medioambiente.

Dentro de la planificación, desarrolla también en su artículo 100 la participación de las CCAA en la planificación energética estatal a través de la Conferencia Sectorial de Energía para la preparación, desarrollo y aplicación de la planificación ${ }^{48}$.

Finalmente, en este ámbito, el proyecto de ley de economía sostenible prevé el adecuado seguimiento y evaluación del cumplimiento de los objetivos fijados, la realización cada cuatro años de una evaluación de los distintos instrumentos de planificación incluidos en esta Ley, en concreto de la planificación indicativa del modelo de generación de energía, la planificación vinculante de las infraestructuras y redes de energía, los planes de energías renovables, los planes nacionales y programas de ahorro y eficiencia energética.

\section{LA EVAlUACIÓN AMBIENTAL DE PLANES Y PROGRAMAS ENERGÉTICOS}

\section{Introducción, concepto y regulación}

Uno de los objetivos prioritarios de la planificación energética junto a la eficiencia, seguridad y diversificación de las actividades de producción, transformación, transporte y usos de la energía, consiste en la preservación de la calidad medioambiental.

\footnotetext{
${ }^{48}$ En concreto se establece que la Conferencia Sectorial de Energía la Conferencia conocerá necesariamente de las siguientes actuaciones:

a) Preparación y formulación de los Planes Nacionales y, en su caso, de los Planes de las Comunidades Autónomas, en los ámbitos del ahorro, la eficiencia energética y las energías renovables.

b) Coordinación, gestión y seguimiento de la aplicación por las

Comunidades Autónomas de la política energética definida en la normativa estatal y en los correspondientes planes

c) Intercambio de información y estadísticas energéticas

d) Formulación, financiación y gestión de proyectos y actuaciones concretas.
} 
La evaluación ambiental en los niveles estratégicos de decisión tiene como fin orientar la planificación desde el principio hacia los objetivos ambientales, integrando éstos con los de la planificación, para hacerla más sostenible.

Las disposiciones aplicables relativas a la ordenación del territorio y al medio ambiente se han de tener muy en cuenta a la hora de proyectar una instalación energética. Si la instalación es para la evacuación de la energía eléctrica producida a la red general de transporte, por estar ésta sometida a la planificación vinculante estatal, los problemas no surgirán tanto para el titular del proyecto, como que será más bien un problema previo de coordinación administrativa y de previsión planificadora. ${ }^{49}$ Es por ello que no sólo los proyectos tienen que estar sometidos a evaluación ambiental sino también ahora los planes o programas que sirven de marco a tales proyectos.

La evaluación es una técnica dirigida a prevenir ciertos efectos negativos y para prevenirlos se analizan los que podría producir el plan, las diferentes alternativas, para antes de su aprobación introducir las medidas oportunas. Por tanto, con ella se pone de manifiesto uno de los principales principios del Derecho Ambiental: el principio de prevención ${ }^{50}$ mediante la operación de anticipar los posibles efectos ambientales que pudiera tener un plan y en consecuencia adoptar las medidas que se consideren necesarias para evitarlo. La evaluación también se justifica en el principio de cautela mediante la integración de la componente "riesgo ambiental" en la preparación y adopción de planes y programas que pueden tener repercusiones significativas sobre el medio ambiente. A juicio de VERDÚ AMORÓS, la evaluación ambiental de planes y programas se basa en cuatro principios básicos: integración, cautela, prevención y participación ${ }^{51}$, realmente principios aplicables a todas las técnicas de intervención administrativa sobre el medio ambiente.

La Evaluación Ambiental Estratégica de Planes y Programas (EAE) es un procedimiento evaluatorio de la incidencia ambiental de los planes y programas de carácter anticipado e independiente de la evaluación de impacto ambiental de proyectos (EIA). La EAE trata de integrar las consideraciones ambientales en la elaboración de planes y programas que

\footnotetext{
${ }^{49}$ LÓPEZ SAKO, M.J., Regulación y autorización de los parques eólicos, Civitas, Madrid, 2009, p.305.

${ }^{50}$ Sobre los principios del Derecho ambiental, véase por todos, LOPERENA ROTA, D., Los principios del Derecho Ambiental, Civitas, Madrid, 1998; BETANCOR RODRÍGUEZ, A., Instituciones de Derecho Ambiental, La Ley, 2001.

${ }^{51}$ VERDÚ AMORÓS, M., "Una visión sintética del significado de la evaluación ambiental estratégica", Revista Aranzadi de Derecho Ambiental, núm. 10, 2006, p.88.
} 
puedan tener efectos sobre el medio ambiente. Estamos ante un nuevo tipo de evaluación ambiental que comparte muchos aspectos con la evaluación de impacto ambiental de proyectos y que ante todo supone una especie de adelantamiento de las barreras de protección ambiental respecto de determinadas actuaciones que van a tener a futuro un impacto ambiental. De esta manera se somete a evaluación ambiental los planes o programas en que en distintos ámbitos van a constituir el marco de ulteriores proyectos concretos que se deberán someter a evaluación de impacto ambiental de proyectos. Las instalaciones de generación de energía provocan importantes impactos ambientales y es por ello que con carácter general se someten a evaluación de impacto ambiental. Ahora bien, nuestro ordenamiento jurídico con carácter previo prevé el sometimiento de la planificación energética a evaluación ambiental estratégica.

El antecedente es la NEPA (National Environmental Policy Act) norteamericana de 1969. En el ámbito de la UE se implementa después de la EIA de proyectos a través de la Directiva 2001/42/CE, de 27 de junio de 2001, relativa a la evaluación de los efectos de determinados planes y programas en el medio ambiente ${ }^{52}$.

A nivel estatal esta Directiva fue transpuesta a nuestro ordenamiento jurídico con cierto retraso por la Ley 9/2006, de 28 de abril, de evaluación ambiental de planes y programas (LEAE) que introduce en la legislación española a nivel estatal y con carácter básico la evaluación ambiental de planes y programas, como un instrumento de prevención que permita integrar los aspectos ambientales en la toma de decisiones de planes y programas

\footnotetext{
${ }^{52}$ La evaluación ambiental de planes y programas no ha sido tratada con tanta profusión por la doctrina como la evaluación ambiental de proyectos, si bien ha sido abordada de manera singular entre otros por CALVO HERRERO, R., "Evaluación estratégica ambiental de planes y programas", Revista interdisciplinar de gestión ambiental, núm. 24, 2000; ROSA MORENO, J., "La evaluación ambiental estratégica en la planificación de infraestructuras", Actas del III Congreso Nacional de Derecho Ambiental, 2000; GARRIDO CUENCA, N., "La evaluación ambiental estratégica de políticas, planes y programas", Revista Aranzadi de Derecho Ambiental, núm. 5, 2004; FERNÁNDEZ VALVERDE, R., "Evaluación ambiental estratégica", Estudios de derecho judicial, núm. 82, 2005; RAZQUIN LIZARRAGA, J.A., "Evaluación ambiental de planes y programas", Diccionario de Derecho Ambiental, Iustel, Madrid, 2006; VERDÚ AMORÓS, "Una visión sintética..." cit.; y Ámbito de aplicación y procedimiento de la evaluación ambiental estratégica, Aranzadi, Cizur Menor, 2008; YAÑEZ DÍAZ, C. "La evaluación ambiental de los planes y programas en la normativa estatal y madrileña", Revista jurídica de la Comunidad de Madrid, núm.23, 2006; GALERA RODRIGO, S., La evaluación ambiental de planes y programas, Montecorvo, Madrid, 2006; ENTRENA RUIZ, D., "La Ley 9/2006, de 28 de abril, sobre evaluación de los efectos de determinados planes y programas en el medio ambiente: contenido y consecuencias, en particular en el ámbito urbanístico", Ecosostenible, núm. 16, 2006; SANZ RUBIALES, I., "Notas sobre el régimen jurídico de la evaluación estratégica de planes en la Ley 9/2006", Revista Aranzadi de Derecho Ambiental, núm. 12, 2007; MANTECA VALDELANDE, V., "Evaluación ambiental de planes y programas", Actualidad administrativa, núm. 1, 2007. FERNANDEZ TORRES, J.R., La evaluación ambiental estratégica de planes y programas urbanisticos, Aranzadi, Cizur Menor, 2009.
} 
públicos. Todo ello sin perjuicio de que muchas CCAA ya habían establecido su propia normativa en materia de evaluación ambiental estratégica incluso con carácter previo a la propia transposición de la Directiva ${ }^{53}$.

La LEAE trata de promover un desarrollo sostenible, conseguir un elevado nivel de protección del medio ambiente y contribuir a la integración de los aspectos ambientales en los planes y programas a realizar, mediante una evaluación ambiental de aquellos que puedan tener efectos significativos sobre el medio ambiente. El objetivo de la EAE no es otro que el de adoptar en el seno del plan la mejor y más eficiente decisión final desde un punto de vista del desarrollo sostenible ${ }^{54}$.

Define como evaluación ambiental aquel proceso que permite la integración de los aspectos ambientales en los planes y programas mediante la preparación del informe de sostenibilidad ambiental, de la celebración de consultas, de la consideración del informe de sostenibilidad ambiental, los resultados de las consultas y la memoria ambiental así como el suministro de información sobre la aprobación de dichos planes y programas.

Por planes y programas se entiende el conjunto de estrategias, directrices y propuestas que prevé una Administración pública para satisfacer necesidades sociales, no ejecutables directamente, sino a través de su desarrollo por medio de un conjunto de proyectos.

La evaluación ambiental estratégica es una evaluación anticipada de las repercusiones de los proyectos respecto de aquellas características de los mismos que vienen predeterminadas en un plan o programa, siendo la principal característica predeterminada la de su emplazamiento. ${ }^{55}$ La EAE es un procedimiento reglado de análisis sistemático de los efectos ambientales a los niveles superiores de decisión tratando de integrar las sostenibilidad en la elaboración de planes y programas. Como señala J.A. RAZQUIN LIZARRAGA, se trata de un proceso sistémico, integrado y global de autoevaluación evitando la tiranía de las pequeñas decisiones y superar o cubrir las insuficiencias de la EIA.

\footnotetext{
${ }^{53}$ Sobre la transposición de la Directiva EAE en España y en otros países de la UE, véase NIETO MORENO, J.E., "La transposición de la Directiva 2001/42/CE: modelos y cuestiones abiertas", VVAA, Evaluación de Impacto Ambiental. Evolución normativo-jurisprudencial, cuestiones procedimentales y aplicación sectorial, Atelier, Barcelona, 2009.

${ }^{54}$ BARNÉS, J., "Sobre el procedimiento administrativo evolución y perspectivas", Barnés, J (ed.), Innovación y reforma en el Derecho Administrativo, Global Law Press, Sevilla, 2006, p. 287.

${ }^{55}$ Así lo señala SCHMIDT-EICHSTAEDT, G., "La Directiva 2001/42/CE, sobre evaluación ambiental estratégica, apuntes desde la República Federal de Alemania", Revista Aranzadi de Derecho Ambiental, núm. 4, 2003, p.29.
} 
Las notas diferenciales entre la EIA y la EAE se refieren más a conceptos que a aspectos geográficos o técnicos; tiene lugar en un momento más temprano de la toma de decisiones; la EAE contiene un enfoque proactivo o adaptativo más que reactivo o semiadaptivo; considera un amplio elenco de potenciales alternativas; temprana consideración de los efectos acumulativos; énfasis en la determinación de objetivos ambientales, en cuestiones de sostenibilidad; y una perspectiva amplia y menor nivel de detalle $^{56}$. A diferencia de lo que sucede con la evaluación de proyectos, que culmina con un juicio sobre la conveniencia o no de la aprobación del proyecto correspondiente, la evaluación de planes concluye con un juicio sobre cómo habrán de integrarse los aspectos ambientales en el plan proyectado, cómo debe redactarse el plan para que sea compatible con los objetivos ambientales perseguidos, constituyendo una técnica de mejora del plan para incorporar a su contenido ciertos aspectos que se consideran relevantes 57 .

La evaluación ambiental de la planificación energética debe servir para incorporar la variable ambiental en dicho proceso, interviniendo en aspectos tales como la elaboración de los diagnósticos, definición de objetivos y alternativas, propuesta de actuaciones y evaluación y selección de las mismas, así como en la toma de decisiones en cada una de esas fases.

\section{Normativa autonómica en materia de Evaluación Ambiental Estratégica}

Además de la planificación energética estatal existe una planificación energética a nivel autonómico en ejercicio de las competencias que la Constitución y sus respectivos estatutos atribuyen a las CCAA. Evidentemente esta planificación en la medida en que cumpla los requisitos que establece la legislación de EAE debe someterse a tal evaluación de acuerdo con lo establecido en la legislación estatal o en su respectiva normativa autonómica si la hubiere aprobado.

\footnotetext{
${ }^{56}$ Cfr. RAZQUIN LIZARRAGA, J.A. "Evaluación ambiental de planes y programas", Lozano Cutanda, B., Alonso García, E. (dirs.), Diccionario de Derecho Ambiental, Iustel, Madrid, p. 260.

${ }^{57}$ BETANCOR RODRÍGUEZ, A., Mejorar la regulación. Una guía de razones y medios, Fundación Rafael del Pino-Marcial Pons, Madrid, 2009, p. 271.
} 
Son numerosas las normas autonómicas ${ }^{58}$ que han regulado la evaluación ambiental de planes y programas, a saber: Aragón, Ley 7/2006, de 22 de junio, de medio ambiente (arts. 11 y ss.); Cantabria, Ley 17/2006, de 11 de diciembre, de control ambiental integrado (arts. 25 y ss.); Castilla-La Mancha, Ley 4/2007, de 28 de marzo, de evaluación ambiental (arts. 25 y ss); Cataluña, Ley 6/2009, de evaluación ambiental de planes y programas; Illes Balears, Ley 11/2006, de 14 de septiembre, de evaluaciones de impacto ambiental y evaluaciones ambientales estratégicas; La Rioja, Ley 5/2002, de 8 de octubre, de protección del medio ambiente (arts. 27 y ss.); Comunidad de Madrid, Ley 2/2002, de 19 de junio, de evaluación ambiental (arts. 12 y ss.); Murcia, Ley 4/2009, de 14 de mayo, de protección ambiental integrada (arts.100 y ss); Navarra, Ley Foral 4/2005, de 22 de intervención para la protección ambiental (arts.30 y ss.); y País Vasco, Ley 3/1998, de 27 de febrero, del medio ambiente.

Como se ve algunas de las leyes autonómicas citadas regulan exclusivamente la EAE (caso de la catalana), la mayoría dentro las diferentes técnicas de intervención previstas en leyes generales, y otras regulan la evaluación ambiental de planes y programas en un único procedimiento de evaluación ambiental de proyectos y planes (caso de la ley vasca y de la ley riojana).

Como es lógico y en coherencia con el sistema ya establecido por el TRLEIA 1/2008, la LEAE establece que la competencia para llevar a cabo la EAE respecto de Planes estatales será del órgano ambiental estatal (Ministerio de Medio ambiente, desarrollo rural y marino) y la EAE será competencia de las CCAA respecto de los planes que se aprueben por la Administración autonómica y local ${ }^{59}$. Como señala SANZ RUBIALES, la LEAE no ha cedido a la interpretación de la evaluación de planes como actividad de ejecución en materia de medio ambiente ya que ello supondría la entrega a las CCAA de la competencia de EAE respecto de todos los planes ${ }^{60}$. La LEAE como hemos señalado,

\footnotetext{
${ }^{58}$ Sobre las normas autonómicas que han llevado a cabo una regulación de la evalucación ambiental estratégica, véase el completo estudio sobre cada una de las mismas en FERNÁNDEZ TORRES, La evaluación ambiental estratégica cit., pp. 27-29. Igualmente, Cfr. LÓPEZ RAMÓN, Observatorio de Politicas Ambientales 2009 cit. y también en los anteriores.

${ }^{59}$ En el caso local, la LEAE no señala la competencia sino que remite a la legislación autonómica en su artículo 5.2 "En el caso de planes y programas cuya elaboración o aprobación corresponda a las entidades locales, las actuaciones previstas en esta Ley corresponderán a la Administración que determine la legislación autonómica" que en todo caso atribuye la competencia al órgano ambiental autonómico dada la tradicional insuficiencia personal, técnica y material de las EELL para llevarla a cabo.

${ }^{60}$ SANZ RUBIALES, I., "Notas..." cit., p. 57. También aborda esta cuestión VERDÚ AMORÓS, M., Ámbito de aplicación y procedimiento de la evaluación ambiental estratégica, Aranzadi, Cizur Menor, 2008, p. 140.
} 
sigue aquí a la estructura del TRLEIA según el cual la competencia sustantiva determina también la competencia ambiental de acuerdo con el principio de integración ${ }^{61}$.

\section{3. Ámbito de aplicación: inclusión de los planes energéticos.}

La LEAE en su artículo 3 al establecer qué planes deben obligatoriamente someterse a EAE antes de su aprobación, incluye los planes relacionados con la energía. Obviamente hablamos de planes aprobados por las respectivas Administraciones ya sea estatal o autonómica $^{62}$. Así, sólo se someten a EAE obligatoria aquellos planes que:

a) Puedan tener efectos significativos sobre el medio ambiente. La LEAE señala que en todo caso se entenderán que tienen efectos significativos sobre el medio ambiente los que establezcan el marco para la futura autorización de proyectos legalmente sometidos a EIA en las siguientes materias: agricultura, ganadería, silvicultura, acuicultura, pesca, minería, energía, minería, industria, transporte, gestión de residuos, gestión de recursos hídricos, ocupación del dominio público marítimo terrestre, telecomunicaciones, turismo, ordenación del territorio urbano y rural, o del uso del suelo. ${ }^{63}$

b) Se aprueben o elaboren por una Administración Pública.

c) $\mathrm{Su}$ elaboración y aprobación venga exigida por una disposición legal o reglamentaria o por acuerdo del Consejo de Ministros o del Consejo de Gobierno de una Comunidad Autónoma.

\footnotetext{
${ }^{61}$ Sobre la constitucionalidad de esta previsión y su interpretación véase las SSTC 13/1998 y 101/2006.

${ }^{62}$ En relación con el ámbito de la EAE, VERDÚ AMORÓS, Ámbito de aplicación ... cit., pp. 26-94.

${ }^{63}$ En el sistema de lista que introducen tanto la ley como la Directiva se incluyen los sectores de la energía y la ordenación del territorio.
}

La lista hace referencia a los planes y programas cuyo contenido establezca el marco para la autorización de proyectos enumerados en los Anexos I y II de la Directiva EIA.

De esta manera, todos los planes energéticos que hagan referencia o supongan el marco de la ulterior implantación de proyectos o instalaciones energéticas que deban someterse a EIA, han de evaluarse previamente a través del instrumento de la evaluación ambiental estratégica. Por consiguiente cualquier instalación de generación de energía estará condicionada doblemente desde un punto de vista ambiental: primero a través de la evaluación ambiental estratégica que condicionará aspectos sobre su idoneidad y ubicación, y después, a nivel singular se someterá a evaluación de impacto ambiental sin perjuicio de que además pueda estar sujeta a autorización ambiental integrada.

El Real Decreto-Legislativo 1/2008, incluye tanto dentro de su Anexo I como dentro del Anexo II numerosos proyectos de instalaciones de energía que deben someterse a evaluación de impacto ambiental. En unos casos obligatoriamente (anexo I) y en otros en función de la decisión que sobre el concreto proyecto o instalación decida la Administración ambiental competente (anexo II). 
Sobre los planes aprobados en las citadas materias, la LEAE establece una presunción iuris et de iure de sus efectos significativos sobre el medio ambiente ${ }^{64}$. En todo caso quedan también sujetos a EAE los elaborados por la Administración y aprobados por el Parlamento, caso de los planes energéticos como vimos supra.

Evidentemente, a la vista del artículo 3 LEAE, la planificación de los sectores del gas y electricidad está sujeta a evaluación ambiental estratégica por lo que los requisitos establecidos por la LEAE incluyen de lleno la planificación energética prevista en los artículos 4 LSE y 4 LSH.

Evidentemente, el sector energético y su planificación tienen efectos sobre el medio ambiente que la profusa legislación ambiental trata de acotar y prevenir ${ }^{65}$. El sometimiento de tal planificación a la técnica de la evaluación ambiental viene en cierto modo reconocida por la redacción del artículo 4.3 LSE en el que señala que en la planificación se deberán incluir los criterios de protección ambiental que condicionen las actividades de suministro de energía eléctrica, con el fin de minimizar el impacto ambiental producido por dichas actividades.

En la evaluación ambiental estratégica de un plan energético se deben analizar las alternativas energéticas, tanto desde el lado de la oferta como desde el de la demanda, un análisis de las diferentes posibilidades que ofrecen los productos energéticos sustituibles entre sí a efectos de elegir la mejor opción. También permitiría, en cada sector energético, analizar las opciones de transformación o de generación frente a las opciones de demanda, tales como, por ejemplo, la promoción de mecanismos de gestión de demanda frente a la alternativa de construir una nueva central parar satisfacer una punta del sistema. En todos estos análisis se deberían contemplar las variables económicas, de seguridad de suministro y medioambiental.

Como se ve entre los planes, programas promovidos $\mathrm{y}$ aprobados por las Administraciones Públicas competentes que tienen que someterse necesariamente a EAE tenemos los del sector energético. Por consiguiente, como puede verse todos los planes energéticos tienen que estar sometidos necesariamente a EAE antes de su correspondiente aprobación por parte de la Administración competente. Las diferentes leyes autonómicas

\footnotetext{
${ }^{64}$ SANZ RUBIALES, “Notas...” cit., p. 50.

${ }^{65}$ Cfr. RUIZ DE APODACA ESPINOSA, A., "Los condicionantes ambientales en la implantación de instalaciones de generación de energía eléctrica", Noticias de la Unión Europea, núm. 284, 2008, pp. 77 91.
} 
que regulan la EAE, evidentemente, también someten a EAE los planes energéticos cuya aprobación sea competencia de la respectiva Comunidad Autónoma. Así, por ejemplo, la reciente Ley 6/2009, de 28 de abril, de evaluación ambiental de planes y programas, incluye en su ámbito de aplicación, El Plan de energía de Cataluña y El Plan de implantación de la energía eólica en Cataluña.

Queda claro que la EAE se aplica exclusivamente a los planes públicos, es decir, los previstos por cualquiera de las Administraciones Públicas. En consecuencia no es de aplicación a los distintos planes o estrategias de empresas privadas (ej. Empresas energéticas) que pueden prever en planes la ejecución de distintos proyectos $\mathrm{o}$ instalaciones que ulteriormente deberán someterse a evaluación de impacto ambiental de proyectos.

Por otro lado, el hecho de que un determinado Plan o Estrategia que previendo proyectos concretos se someta a EAE no supone exención de la obligación de someter tal proyecto a evaluación de impacto ambiental en el caso de que deba someterse. No obstante, la EAE que se haya realizado de un plan o programa se tendrá en cuenta en la EIA de los proyectos que la desarrollen tal y como establece la Disposición Adicional tercera de la LEAE “La evaluación ambiental realizada conforme a esta Ley no excluirá la aplicación de la legislación sobre evaluación del impacto ambiental de proyectos. La evaluación ambiental que se haya hecho a un plan o programa se tendrá en cuenta en la evaluación de impacto ambiental de los proyectos que lo desarrollen." Se trata de dos técnicas distintas aunque comparten la misma dinámica procedimental y la finalidad ambiental que no se solapan y que tendrán carácter sucesivo.

La evaluación ambiental que se haya hecho a un plan o programa se tendrá en cuenta en la evaluación de impacto ambiental de los proyectos que lo desarrollen. Ahora bien, podría ocurrir que una infraestructura de energía prevista en la correspondiente planificación vinculante sometida a EAE, con posterioridad tuviera problemas en su autorización por cuestiones ambientales relacionadas con la EIA del proyecto singular en cuestión. En este caso ¿pudiera ser la DIA negativa pese a haber sido contemplado el citado proyecto en el plan aprobado de acuerdo con la EAE realizada?, a mi juicio cabría perfectamente esa posibilidad aunque fuese evidente la disconformidad entre ambos instrumentos de control ambiental previo (EAE) y posterior (EIA). 


\subsection{Revisiones menores de la planificación}

En relación con el ámbito, una cuestión relacionada con la exigencia o no de EAE puede plantearse respecto de las revisiones de esta planificación energética que suelen ser frecuentes, así como los planes anuales de desarrollo de una planificación interanual. Así por ejemplo el actual plan energético en los sectores del gas y la electricidad prevé que el proceso de planificación se revisará globalmente cada cuatro años y anualmente se aprobará un Programa Anual de Instalaciones de las Redes de Transporte.

En estos casos se plantea la duda de si requerirán de nueva EAE. Caso de que estemos ante revisiones menores, de acuerdo con el artículo 2.h LEAE $^{66}$ no deben requerir nueva EAE, ahora bien si tales revisiones o planes anuales tuvieran efectos significativos, en tal caso sí sería necesaria nueva EAE de acuerdo con el artículo 3.3b) LEAE. Como señala SANZ RUBIALES, se trata aquí de un concepto jurídico indeterminado, por lo que se tiene que valorar el contexto del plan o programa que se está modificando y la probabilidad de que tal modificación tenga o no efectos significativos sobre el medio ambiente ${ }^{67}$.

\subsection{Concurrencia de los planes energéticos con otros planes sectoriales o autonómicos}

La planificación energética, principalmente eléctrica, evidentemente no es autónoma ya que puede estar relacionada con otras planificaciones sectoriales también sometidas a EAE. En este punto la planificación en general y la EAE en particular exige una elevada coordinación entre las Administraciones implicadas. Así la LEAE menciona expresamente la necesidad de que las Administraciones implicadas se coordinen y colaboren entre sí, lo que se manifiesta en su relación de la planificación sujeta a EAE con otros planes que puedan incidir sobre el mismo espacio físico ${ }^{68}$.

\footnotetext{
${ }^{66}$ Modificaciones menores: cambios en las características de los planes o programas ya aprobados o adoptados que no constituyen variaciones fundamentales de las estrategias, directrices y propuestas o de su cronología pero que producen diferencias en las características de los efectos previstos o de la zona de influencia.

${ }^{67}$ SANZ RUBIALES, “Notas..." cit., p. 54. En el mismo sentido, FERNÁNDEZ TORRES, La evaluación ambiental estratégica cit., pp. 106-107 quien además hace referencia expresa al Informe de la Dirección General de Medio Ambiente de la Comisión Europea sobre la Directiva 2001/42/CE y qué debe entenderse a tales efectos por modificaciones menores.

${ }^{68}$ Sobre esta cuestión ENTRENA RUIZ, D. “La Ley 9/2006...” cit., pp.28-30.
} 
Con el fin de evitar reiteraciones, el artículo 6 LEAE establece que "Cuando exista una concurrencia de planes o programas promovidos por diferentes Administraciones públicas, éstas deberán adoptar las medidas necesarias con el fin de que puedan complementarse y para evitar que se produzca una duplicidad de evaluaciones, asegurando que todos los efectos ambientales significativos de cada uno son convenientemente evaluados." Para evitar estas duplicidades innecesarias, prevé en su D.Ad. $5^{\text {a }}$ que "no deberán someterse a un nuevo proceso de evaluación como consecuencia de la elaboración y aprobación de un plan de ordenación urbanística o territorial las infraestructuras de titularidad estatal en cuya planificación sectorial se haya realizado la evaluación ambiental conforme a lo dispuesto en esta Ley. En tales casos, la Administración pública competente para la aprobación del plan de ordenación urbanística o territorial podrá exigir que se tengan en cuenta los aspectos no específicamente considerados en la primera evaluación ambiental."

Los conflictos en cuanto a la planificación energética vinculante se pueden plasmar con las competencias que tienen las CCAA en materia de ordenación del territorio. Como señala LÓPEZ RAMÓN ${ }^{69}$, en estos casos el conflicto entre energía y ordenación del territorio se ha decantado a favor de la energía. Algo que ya se prevé de manera expresa en el artículo 5.1 de la $\mathrm{LSE}^{70}$ y en el 5.1 $\mathrm{LSH}^{71}$.

En opinión de LÓPEZ RAMÓN, se ha llegado así a una desconsideración de los intereses públicos no eléctricos en relación con la protección del medio ambiente, la

\footnotetext{
${ }^{69}$ LÓPEZ RAMÓN, F. "Infraestructuras de energía y ordenación del territorio”, El derecho de la energía. XV Congreso italo-español de profesores de Derecho administrativo, IAAP, Sevilla, 2006, p.88.

${ }^{70} 5.1$ LSE "La planificación de las instalaciones de transporte y distribución de energía eléctrica cuando éstas se ubiquen o discurran en suelo no urbanizable, deberá tenerse en cuenta en el correspondiente instrumento de ordenación del territorio. Asimismo, y en la medida en que dichas instalaciones se ubiquen en cualesquiera de las categorías de suelo calificado como urbano o urbanizable, dicha planificación deberá ser contemplada en el correspondiente instrumento de ordenación urbanística, precisando las posibles instalaciones, calificando adecuadamente los terrenos y estableciendo, en ambos casos, las reservas de suelo necesarias para la ubicación de las nuevas instalaciones y la protección de las existentes."

71 5.1 LSH "La planificación de instalaciones de transporte de gas y de almacenamiento de reservas estratégicas de hidrocarburos, así como los criterios generales para el emplazamiento de instalaciones de suministro de productos petrolíferos al por menor, deberán tenerse en cuenta en el correspondiente instrumento de ordenación del territorio, de ordenación urbanística o de planificación de infraestructuras viarias según corresponda, precisando las posibles instalaciones, calificando adecuadamente los terrenos y estableciendo las reservas de suelo necesarias para la ubicación de las nuevas instalaciones y la protección de las existentes". Sobre el artículo 5 LSH relativo a la coordinación con los planes urbanísticos y de infraestructuras viarias, véase CALANCHA MARZANA, F. en VVAA, Manual del Sector de Hidrocarburos cit., pp. 77-82. En materia de planificación hidrológica esta misma cuestión es abordada brillantemente in totum en PALLARÈS SERRANO, La planificación hidrológica cit.
} 
tutela del paisaje, la utilización racional de los recursos naturales y la defensa del patrimonio cultural. No obstante esta afirmación debe ser matizada en el sentido de que la planificación energética antes de llevarse a cabo en lo que se refiere a las infraestructuras necesariamente deberá tener en cuenta la planificación territorial existente y, por supuesto, integrar en ella todas las variables ambientales necesarias, esa es la razón precisamente de la $\mathrm{EAE}^{72}$. Todo proyecto se realiza sobre el territorio, sobre el suelo, y los citados planes con sus respectivas EAE deberán tener presentes también los planes urbanísticos y de ordenación del territorio y sus respectivas evaluaciones ${ }^{73}$.

De de hecho, la planificación energética actual viene condicionada o debe tener en cuenta a la hora de llevar a cabo la EAE otros planes y evitar redundancias. Es el caso del Plan de Energías Renovables 2005-2010, de la Estrategia de Ahorro y Eficiencia Energética de España y sus sucesivos Planes de Acción, del Plan Nacional de Asignación 2008-2012, la Estrategia Española de Cambio Climático y energía Limpia. Horizonte 2007-2012-2020 y por supuestos los compromisos medioambientales que afectan al sector energético y otros planes sectoriales, como el relativo a la minería del carbón. Como señala el actual Plan 2008-2016 en los sectores de gas y electricidad, los objetivos medioambientales, bien provenientes de la política nacional o derivados de compromisos internacionales, representan uno de los condicionamientos más relevantes en la planificación al determinar indirectamente los tipos de energías a consumir, tecnologías de transformación y uso final, y evolución de la eficiencia energética.

En definitiva, la coordinación y la armonización de los distintos ámbitos e intereses en juego (públicos, privados, económicos, sociales o de desarrollo), resultan imprescindibles para cohonestarlos con los intereses ambientales, condición necesaria para la consecución del desarrollo sostenible ${ }^{74}$.

\footnotetext{
${ }^{72}$ Sobre la incidencia que la EAE puede tener en la planificación territorial véase GARCÍA BELLIDO, J. "Hacia un nuevo control democrático de la planificación territorial: la evaluación ambiental estratégica de planes y programas", Ciudad y Territorio, Estudios Territoriales, 2002.

${ }^{73}$ Sobre la EAE y la planificación urbanística y territorial, cfr. FERNÁNDEZ TORRES, La evaluación ambiental estratégica cit.

${ }^{74}$ LOZANO CUTANDA, Derecho Administrativo Ambiental cit.,, p.385.
} 


\section{EL PROCEDIMIENTO DE EVALUACIÓN AMBIENTAL ESTRATÉGICA Y SU IMBRICACIÓN EN LA PLANIFICACIÓN ENERGÉTICA ESTATAL}

La LEAE como la gran mayoría de las leyes ambientales que establecen técnicas de intervención es una norma procedimental en la que el procedimiento regulado con cada una de sus fases es el que va a determinar el contenido de la EAE no siendo una mera sucesión de trámites tendentes en concluir en una resolución más o menos ajustada a Derecho. El procedimiento aquí reviste una gran importancia, contiene una serie de elementos con sustancia propia conformadores del contenido del acto dado que nos encontramos ante una norma programática, finalista, que establece un objetivo concreto que se ha de determinar con los elementos del procedimiento. Además el procedimiento adquiere una gran relevancia como proceso de toma de decisiones y constituye una garantía de acierto y una forma también de legitimación democrática en la medida en que se de cabida a la participación en la toma de decisiones. Como señala J. BARNÉS, "La idea que subyace del procedimiento de EAE se encuentra en las antípodas de una comprensión más formalista, para la que lo relevante no es sino que el trámite se evacúe en tiempo y forma por el órgano competente; y no en cambio, el contenido y la sustancia misma de esos trámites, más importantes en cierto modo que la decisión final si, además de la garantía de los derechos de los interesados, importa alcanzar la mejor y más eficaz de las resoluciones ${ }^{75}$."

La Directiva 2001/42/CE de EAE no estableció el procedimiento, dejando éste en manos de cada uno de los Estados. No obstante en ella se fijan una serie de reglas generales:

- La EAE ha de ser previa, se efectuará durante la preparación y antes de la adopción del plan o programa.

- Se integra en el procedimiento administrativo aplicable a la adopción del plan o programa.

Si se produce la concurrencia de planes o programas promovidos por diferentes Administraciones Públicas, éstas deberán adoptar las medidas necesarias para evitar que se produzca una duplicidad de evaluaciones, asegurando que todos los efectos ambientales significativos de cada uno son convenientemente evaluados. En el ámbito energético pueden concurrir además de los planes estatales los respectivos planes energéticos autonómicos.

\footnotetext{
${ }^{75}$ BARNÉS, “Sobre el procedimiento administrativo..." cit., p. 288.
} 
Para ver de qué manera se imbrica y aplica el procedimiento de EAE en la planificación energética, la explicación de las diferentes fases de este procedimiento vendrá acompañada de los datos que demuestran como el Estado ha implementado esta técnica en la reciente planificación energética. Esta "Planificación de los Sectores de Electricidad y Gas 2008-2016. Desarrollo de las Redes de Transporte", aprobado por el Consejo de Ministros de 30 de mayo de 2008, integra el desarrollo de los sistemas gasista y eléctrico en dicho horizonte temporal, incluyendo previsiones de demanda eléctrica y de gas, recursos necesarios para satisfacerla y detalle pormenorizado de las redes de transporte de electricidad y gas a construir en dicho período, con carácter vinculante, realizando la estimaciones económicas correspondientes.

La planificación hasta ahora vigente en materia energética, derivada de la LSE y la LSH, fue aprobada por el Gobierno el 2 de septiembre de 2002 bajo el título "Planificación de los sectores de la Electricidad y el Gas. Desarrollo de las redes de transporte 2002-2011" y que fue modificada en 2006 con el objetivo de identificar las desviaciones de la previsión de la demanda energética y su cobertura, así como la revisión de la planificación de las redes de transporte del gas y la electricidad.

El proceso de aprobación de la planificación de los sectores de electricidad y gas 20082016 comenzó mediante la Orden ITC/2675/2006, publicada en el BOE de 17 de agosto de 2006. A través de esta orden se convocó a los sujetos del sistema eléctrico, a los sujetos del sistema gasista, Comunidades Autónomas y promotores de nuevos proyectos a la realización de propuestas de desarrollo de las redes de transporte de energía eléctrica y de la red básica de gas natural, así como a la aportación de la información necesaria para llevar a cabo el proceso de planificación. Asimismo, también se convocó a la Corporación de Reservas Estratégicas de Productos Petrolíferos (CORES) a facilitar la información relacionada con las instalaciones de almacenamiento de reservas estratégicas de productos petrolíferos.

Una vez finalizado el plazo de tres meses para la presentación de propuestas por parte de todos los agentes, se elaboró un primer borrador de planificación, el cual fue presentado a las distintas Comunidades Autónomas. Paralelamente, el proceso de planificación tuvo en cuenta no sólo el procedimiento a seguir para este caso en la regulación derivada de la LSE 54/1997 y la LSH 34/1998, sino también la LEAE 9/2006. De este modo, la Planificación de los sectores de electricidad y gas 2008-2016 ha sido sometida al proceso 
de evaluación ambiental estratégica de acuerdo con lo establecido en la LEAE y a ella nos referiremos al hilo de la explicación del procedimiento de EAE.

\section{El informe preliminar y su alcance: 'scoping' o consultas previas}

De acuerdo con la LEAE 9/2006, el proceso de evaluación ambiental estratégica debe comenzar con la preparación de un documento preliminar mediante el cual se informa a las autoridades ambientales y organismos e instituciones interesados sobre el inicio de un proceso de planificación que deberá ser sometido al procedimiento de evaluación de sus efectos ambientales. Ese documento debe informar también sobre los objetivos, alcance y contenido del plan, su desarrollo y sus efectos previsibles sobre el medio ambiente y sobre los elementos estratégicos del territorio, la planificación sectorial implicada, la planificación territorial y las normas aplicables.

En el ámbito de la planificación energética, en este informe es necesario definir alternativas dentro de la planificación con el nivel de detalle y de la información suficiente que resulte de los estudios y simulaciones que se realicen a lo largo del proceso de elaboración de la planificación, cuando puedan surgir alternativas entre diferentes opciones, para conseguir un objetivo determinado.

Se consideran Administraciones públicas afectadas a los efectos de la LEAE aquellas que tienen competencias específicas en las siguientes materias: biodiversidad, población, salud humana, fauna, flora, tierra, agua, aire, factores climáticos, bienes materiales, patrimonio cultural, incluido el patrimonio histórico, paisaje, la ordenación del territorio y el urbanismo. Asimismo la consulta se puede ampliarse a otras personas físicas o jurídicas, públicas o privadas, vinculadas a la protección del medio ambiente.

Tras identificar y consultar a las Administraciones públicas afectadas, al público interesado y, en su caso, a otras personas físicas o jurídicas, públicas o privadas vinculadas a la protección ambiental, el órgano ambiental determinará la amplitud y nivel de detalle del informe de sostenibilidad ambiental. Este alcance se comunicará al órgano promotor mediante un documento de referencia que incluirá además los criterios ambientales estratégicos e indicadores de los objetivos ambientales y principios de sostenibilidad aplicables en cada caso. 
Esta fase no difiere de las denominadas consultas previas en el procedimiento de EIA previas a la redacción del estudio de impacto ambiental de un proyecto y la realidad es bastante pobre dado que en muchos casos no se producen respuestas.

A nivel estatal y en el caso de la planificación de los sectores de electricidad y gas y de acuerdo con el artículo 16 de la Ley 9/2006, el órgano ambiental es el Ministerio de Medio Ambiente, Medio Rural y Marino, deberá fijar los contenidos y alcance del informe de sostenibilidad ambiental que deberá realizar el órgano promotor, en este caso el Ministerio de Industria, Turismo y Comercio, y el modo en que se efectuará la consulta pública.

En lo que respecta a la EAE del actual Plan 2008-2016, el proceso de evaluación ambiental estratégica comenzó con la preparación de un informe preliminar mediante el cual se informó a las autoridades ambientales (en el caso de la Planificación 2008-2016, el Ministerio de Medio Ambiente) sobre el inicio de un proceso de planificación que debía ser sometido al procedimiento de evaluación de sus efectos ambientales. Como resultado del examen de ese informe preliminar, el Ministerio de Medio Ambiente fijó los contenidos, criterios y alcance del informe de sostenibilidad ambiental (ISA), a realizar por el Ministerio de Industria, Turismo y Comercio, en el denominado Documento de Referencia.

\section{EI Informe de Sostenibilidad Ambiental}

Tras la fase de consultas previas del promotor y la determinación por parte del órgano ambiental del alcance del informe de sostenibilidad, el promotor del Plan o Programa debe llevar a cabo el citado "Informe de Sostenibilidad Ambiental" en el que deben presentarse los posibles efectos negativos ambientales del plan o programa y las alternativas razonables para evitarlos. Este informe recuerda mucho al estudio de impacto ambiental en la EIA $^{76}$ y es uno de los elementos clave del proceso de evaluación ambiental estratégica, su columna vertebral ${ }^{77}$, la pieza documental fundamental del

\footnotetext{
${ }^{76}$ Sobre los paralelismos entre el Informe de sostenibilidad ambiental en la EAE y el Estudio de impacto ambiental en la EIA, VERDÚ AMORÓS, Ámbito de aplicación... cit., pp. 203-206.

${ }^{77}$ JARIA I MANZANO, J., "La participación del público en la evaluación ambiental estratégica”, Revista Aranzadi de derecho ambiental, núm. 11, 2007, p. 219.
} 
proceso de evaluación ambiental ${ }^{78}$, elemento clave de todo el proceso en torno al cual pivota todo el proceso de evaluación ${ }^{79}$.

En el informe de sostenibilidad ambiental, el órgano promotor debe identificar, describir y evaluar los probables efectos significativos sobre el medio ambiente que puedan derivarse de la aplicación del plan o programa, así como unas alternativas razonables, técnica y ambientalmente viables, incluida entre otras la alternativa cero, que tengan en cuenta los objetivos y el ámbito territorial de aplicación del plan o programa. A estos efectos, se entenderá por alternativa cero la no realización de dicho plan o programa. No obstante, en el ámbito energético como se encarga de reseñar el actual Plan, no fue contemplada la alternativa cero. Esto es así ya que, si de los estudios realizados por los operadores se deduce que existe la necesidad de programar una infraestructura, y es factible realizarla porque exista al menos una traza o ubicación posible desde el punto de vista medioambiental, no existe la posibilidad de no realizar esa infraestructura, ya que existirían potenciales problemas de suministro a la demanda. Por tanto, en el documento sólo aparecerán las actuaciones necesarias y factibles de realizar. La información que debe contener el informe de sostenibilidad ambiental es la que especifica detalladamente el Anexo I de la $\operatorname{LEAE}^{80}$.

\footnotetext{
${ }^{78}$ VERDÚ AMORÓS, Ámbito de aplicación... cit., p. 192.

${ }^{79}$ FERNÁNDEZ TORRES, La evaluación ambiental estratégica cit., p. 118.

${ }^{80}$ Esta información es:
}

“a) Un esbozo del contenido, objetivos principales del plan o programa y relaciones con otros planes y programas conexos.

b) Los aspectos relevantes de la situación actual del medio ambiente y su probable evolución en caso de no aplicar el plan o programa.

c) Las características ambientales de las zonas que puedan verse afectadas de manera significativa.

d) Cualquier problema ambiental existente que sea relevante para el plan o programa, incluyendo en concreto los relacionados con cualquier zona de particular importancia ambiental designada de conformidad con la legislación aplicable sobre espacios naturales y especies protegidas.

e) Los objetivos de protección ambiental fijados en los ámbitos internacional, comunitario o nacional que guarden relación con el plan o programa y la manera en que tales objetivos y cualquier aspecto ambiental se han tenido en cuenta durante su elaboración.

f) Los probables efectos significativos en el medio ambiente, incluidos aspectos como la biodiversidad, la población, la salud humana, la fauna, la flora, la tierra, el agua, el aire, los factores climáticos, los bienes materiales, el patrimonio cultural, incluido el patrimonio histórico, el paisaje y la interrelación entre estos factores.

g) Las medidas previstas para prevenir, reducir y, en la medida de lo posible, contrarrestar cualquier efecto significativo negativo en el medio ambiente por la aplicación del plan o programa. 
El informe de sostenibilidad ambiental, como parte integrante de la documentación del plan o programa, debe ser accesible e inteligible para el público y las Administraciones públicas, y contendrá un resumen no técnico de manera que se posibilite el ejercicio del derecho a la información ambiental y, en su caso, la participación del público interesado.

\section{La necesaria información y participación pública: alegaciones e informes.}

La gobernanza ${ }^{81}$, la transparencia, la información y la participación son ejes fundamentales de todo procedimiento de evaluación ambiental ${ }^{82}$. Durante la determinación del informe de sostenibilidad, el órgano ambiental debe definir las modalidades de información y consulta, así como identificar a las Administraciones Públicas afectadas y al público interesado que debe participar en el proceso de elaboración del informe. Por ello, el procedimiento de EAE prevé que el informe de sostenibilidad ambiental se someta a:

h) Un resumen de las razones de la selección de las alternativas previstas y una descripción de la manera en que se realizó la evaluación, incluidas las dificultades (como deficiencias técnicas o falta de conocimientos y experiencia) que pudieran haberse encontrado a la hora de recabar la información requerida.

La selección de las alternativas en caso de propuestas tecnológicas, incluirá un resumen del estado del arte de cada una y justificará los motivos de la elección respecto a las mejores técnicas disponibles en cada caso.

i) Una descripción de las medidas previstas para el seguimiento, de conformidad con el artículo 15 .

j) Un resumen no técnico de la información facilitada en virtud de los párrafos precedentes.

k) Un informe sobre la viabilidad económica de las alternativas y de las medidas dirigidas a prevenir, reducir o paliar los efectos negativos del plan o programa.

Estos efectos deben comprender los efectos secundarios, acumulativos, sinérgicos, a corto, medio y largo plazo, permanentes y temporales, positivos y negativos".

${ }^{81}$ Sobre la aplicación de la gobernanza a las políticas públicas en España, CERRILLO I MARTÍNEZ, A. en la introducción a la obra que coordina La gobernanza hoy: 10 textos de referencia, INAP, Madrid, 2005 .

${ }^{82}$ Sobre la efectiva participación del público interesado y del público en general en el procedimiento de evaluación ambiental de planes y programas véase los estudios de JARIA I MANZANO, "La participación del público..." cit.; NIETO MORENO, J.E., “¿Protagonistas o actores de reparto? A propósito de los sujetos intervinientes en la evaluación ambiental de planes y programas", Revista Aragonesa de Administración Pública, núm. 31, 2007; NOGUEIRA LÓPEZ, A., "Participación efectiva o quimera procedimental", VVAA, Evaluación de Impacto Ambiental. Evolución normativojurisprudencial, cuestiones procedimentales y aplicación sectorial, Atelier, Barcelona, 2009. También con carácter general sobre los derechos de información y participación en materia ambiental, RAZQUIN LIZARRAGA, J.A. y RUIZ DE APODACA ESPINOSA, A., Información, participación y acceso a la justicia en materia de medio ambiente. Comentario sistemático a la Ley 27/2006, de 18 de julio, Aranzadi, Cizur Menor, 2007. 
- $\quad$ Disposición del público en general.

- Consulta a las Administraciones afectadas ${ }^{83}$.

- $\quad$ Consulta al público interesado ${ }^{84}$.

Para la realización correcta de la EAE es necesario primero obtener el mayor volumen posible de información de calidad tanto del público interesado, como de todas las Administraciones implicadas y ponderar adecuadamente ese caudal de información ${ }^{85}$. Así el citado Informe de Sostenibilidad se debe someter al trámite de Información Pública en el que cualquier persona puede formular alegaciones. El plazo que cita la LEAE es de 45 días. Para que la participación del público sea efectiva y real la información del informe de sostenibilidad deberá ser accesible e inteligible para el público.

Estos requisitos presentes ya en todos los procedimientos ambientales, suponen pasar de la opacidad legal a la transparencia democrática ${ }^{86}$, abandonar las técnicas de participación democrática formal que convertían la información pública en un acto casi clandestino ${ }^{87}$, a otro de auténtica participación real de los ciudadanos en los procesos de planificación. A pesar de que a juicio de VERDÚ AMORÓS, el legislador estatal ha transpuesto de manera cicatera e infravalorando la participación ${ }^{88}$, debe tenerse en cuenta que la información y la participación son dos derechos que la Administración no debe ni puede dejar de lado, más aún tras la aprobación de la ley 27/2006 de información y participación. Es más, a pesar de que la transposición no fuese expresiva admite una

\footnotetext{
${ }^{83}$ Se considerarán Administraciones públicas afectadas, exclusivamente a los efectos de esta Ley, aquellas que tienen competencias específicas en las siguientes materias: biodiversidad, población, salud humana, fauna, flora, tierra, agua, aire, factores climáticos, bienes materiales, patrimonio cultural, incluido el patrimonio histórico, paisaje, la ordenación del territorio y el urbanismo.

${ }^{84}$ a) Toda persona física o jurídica en la que concurra cualquiera de las circunstancias previstas en el artículo 31 LRJPAC.

b) Cualquier persona jurídica sin ánimo de lucro que cumpla los siguientes requisitos:

$1^{\text {o }}$ Que tenga como fines acreditados en sus estatutos, entre otros, la protección del medio ambiente en general o la de alguno de sus elementos en particular, y que tales fines puedan resultar afectados por el plan o programa de que se trate.

$2^{\text {o }}$ Que lleve al menos dos años legalmente constituida y venga ejerciendo de modo activo las actividades necesarias para alcanzar los fines previstos en sus estatutos.

${ }^{85}$ BARNÉS, "Sobre el procedimiento administrativo..." cit., p. 287

${ }^{86}$ GARCÍA BELLIDO, "Hacia un nuevo control democrático...” cit.

${ }^{87}$ MARTÍN MATEO, R. Nuevos instrumentos de tutela ambiental, Trivium, Madrid, 1994, p.25.

${ }^{88}$ VERDÚ AMORÓS, Ámbito de aplicación... cit., p. 241.
} 
interpretación pro participativa sin lugar a dudas, dependerá de cómo se haga efectiva por cada Administración.

Evidentemente a las alegaciones presentadas será necesario contestar motivadamente así lo señala el artículo 21 LEAE “El órgano promotor responderá motivadamente a las observaciones y alegaciones que se formulen en las consultas, a cuyos efectos elaborará un documento en el que se justifique cómo se han tomado en consideración aquéllas en la propuesta de plan o programa incluyendo el informe de sostenibilidad ambiental." De esta manera se hace efectiva la participación pública evitándose la práctica de antaño en otros procedimientos en los que la participación pública era un mero trámite y en el que no era obligatorio siquiera contestar a las alegaciones presentadas.

En el caso del vigente Plan 2008-2016, el Informe de Sostenibilidad Ambiental fue sometido a información pública durante 45 días, tras el anuncio en el BOE del 1 de agosto de 2007. Las alegaciones recibidas fueron estudiadas y tenidas en cuenta, en su caso, en la elaboración del documento de planificación final. Finalmente, como resumen del procedimiento ambiental, se ha realizado una Memoria Ambiental conjuntamente por el Ministerio de Medio Ambiente y el Ministerio de Industria, Turismo y Comercio. ${ }^{89}$

Igualmente se exige la realización de consultas transfronterizas en lo casos en que la ejecución de un plan o programa pueda tener efectos significativos sobre el medio ambiente de otro Estado miembro de la Unión Europea, o cuando un Estado miembro que pueda verse significativamente afectado lo solicite, la Administración pública promotora, a través del Ministerio de Asuntos Exteriores y de Cooperación, comunicará a dicho Estado la posibilidad de abrir un período de consultas bilaterales para estudiar tales efectos, así como las medidas que, en su caso, puedan acordarse para suprimirlos o reducirlos. A tales efectos, se facilitará al Estado miembro en cuestión un ejemplar de la versión preliminar del plan o programa de que se trate y el informe de sostenibilidad ambiental, con anterioridad a su aprobación.

\footnotetext{
${ }^{89}$ La Memoria Ambiental, al igual que el resto de documentos relacionados con el procedimiento de evaluación ambiental estratégica, están disponibles en la página web del Ministerio de Medio Ambiente, www.mma.es
} 


\section{La Memoria Ambiental y su inimpugnabilidad}

\subsection{Elaboración y carácter no vinculante para el promotor}

Con la información obtenida del Informe de Sostenibilidad Ambiental del Programa y las Alegaciones recibidas al mismo en la fase de consulta y el trámite de Información pública se elabora la denominada "Memoria Ambiental" en la que intervienen conjuntamente el órgano promotor y el órgano ambiental competente para evaluar el programa y el Informe de Sostenibilidad.

La memoria ambiental se elabora finalizada la fase de consultas con objeto de valorar la integración de los aspectos ambientales en la propuesta de plan o programa, en la que se analizarán el proceso de evaluación, el informe de sostenibilidad ambiental y su calidad, y se evaluará el resultado de las consultas realizadas y cómo se han tomado en consideración y se analizará la previsión de los impactos significativos de la aplicación del plan o programa. La memoria ambiental contendrá las determinaciones finales que deban incorporarse a la propuesta del plan o programa.

Es necesario destacar que esta fase no se prevé en la Directiva ni tampoco en la legislación autonómica previa a la LEAE por lo que ésta debiera quizá revisarse, dado su carácter básico ${ }^{90}$.

La memoria ambiental es preceptiva y se tendrá en cuenta en el plan o programa antes de su aprobación definitiva. Será realizada, en el ámbito de la Administración General del Estado, de acuerdo con lo establecido en el artículo 22 LEA y, en el ámbito de las Comunidades Autónomas, por el órgano u órganos que éstas determinen, y, en todo caso, con el acuerdo del órgano ambiental.

En el ámbito de la AGE, el citado artículo 22 LEAE establece que "Finalizada la fase de consultas, incluyendo en su caso las consultas transfronterizas, el órgano promotor y el Ministerio de Medio Ambiente elaborarán conjuntamente la memoria ambiental (..)”

La LEAE ha recogido esa formula de memoria ambiental realizada conjuntamente por el órgano ambiental y el órgano promotor a las evaluaciones realizadas en el ámbito de la Administración General del Estado -Arts. 12 y 22- en tanto que, en las realizadas por la Comunidades Autónomas, la Ley se remite a “...el órgano u órganos que éstas determinen, y, en todo caso, con el acuerdo del órgano ambiental." Para dotar de mayor

\footnotetext{
${ }^{90}$ En este sentido, SANZ RUBIALES, “Notas...” cit., p. 64.
} 
independencia y quizá apariencia de veracidad, la memoria ambiental debiera ser elaborada en exclusiva por el órgano ambiental, tal y como señala LOZANO CUTANDA $^{91}$, sin necesidad de contar con el promotor cuya visión evidentemente será más interesada y menos ambiental.

La Memoria de Sostenibilidad deberá contener las determinaciones precisas que deberá contener el Plan o Programa a los meros efectos ambientales. Como ESTEVE PARDO señala, las determinaciones contenidas en la Memoria de Sostenibilidad no son en principio vinculantes para el promotor planificador aunque alguna legislación autonómica resulta más exigente en este punto. ${ }^{92}$

Y es que la LEAE se limita a señalar que el resultado de la memoria ambiental "se tendrá en cuenta en el plan o programa antes de su aprobación definitiva" (Art. 12) y "elaborará la propuesta plan o programa tomando en consideración el informe de sostenibilidad ambiental, las alegaciones formuladas en las consultas, incluyendo en su caso las consultas transfronterizas, y la memoria ambiental" (Art. 13) pero evidentemente sin darle un carácter vinculante lo que quizá hubiera sido deseable.

No existe un mandato de obediencia, de vinculación jurídica, eso sí, existe el mandato jurídico de analizar la memoria y extraer todas aquellas conclusiones que el promotor considere conveniente pero le corresponde la libertad de modificar el plan en los términos que considere que mejor se adaptan a las conclusiones contenidas en la memoria, teniendo sólo la obligación de exponer las razones la integración en el plan de las conclusiones contenidas en la memoria ${ }^{93}$.

A mi juicio, al igual que también lo opino respecto de la DIA en la EIA, la memoria ambiental debiera tener carácter vinculante ya que de no ser así de nada serviría una evaluación ambiental concienzuda en la que se están poniendo de manifiesto aspectos necesarios a tener en cuenta para el planificador respecto de un plan o programa sobre un sector como el energético con importantes efectos ambientales. En este sentido LOZANO

\footnotetext{
${ }^{91}$ LOZANO CUTANDA, Derecho Ambiental Administrativo cit., p. 347.

${ }^{92}$ Es el caso por ejemplo de la Ley 2/2002, de Evaluación Ambiental de la Comunidad de Madrid que establece "Sin perjuicio de lo dispuesto en el artículo 11 de esta Ley, el Informe de Análisis Ambiental favorable será un requisito previo e indispensable para la aprobación del plan o programa y su contenido será vinculante por lo que las condiciones contenidas en dicho informe deberán incluirse expresamente en el plan o programa antes de su aprobación.”

${ }^{93}$ BETANCOR RODRÍGUEZ, A., Mejorar la regulación. Una guía de razones y medios, Fundación Rafael del Pino-Marcial Pons, Madrid, 2009, p. 272.
} 
CUTANDA, entiende que hay que lamentar que para la EAE se haya optado por un sistema tan laxo respecto de la vinculatoriedad de la memoria ambiental lo que perjudica "la ya de por sí escasa virtualidad práctica de este sistema de protección ambiental"

En el caso del Plan 2008-2016, tras elaborar, conjuntamente el Ministerio de Industria con el Ministerio de Medio Ambiente, la memoria ambiental que debe acompañar al plan en cumplimiento de la LEAE, el documento de planificación fue elevado al Consejo de Ministros para su aprobación en mayo de 2008.

\subsection{Inimpugnabilidad}

La EAE es un conjunto de trámites que culmina en un informe que tiene la consideración de acto administrativo de trámite previo e integrante de la decisión que finalmente se adopte. Como ya vimos supra los planes son impugnables pero se plantea nuevamente la cuestión de si la EAE es impugnable separadamente del plan que se adopte o si se quiere impugnar lo que deberemos hacer es impugnar el citado plan con base en la inadecuación de la EAE ya sea por su contenido o por no haberse respetado el procedimiento previsto en la LEAE.

La doctrina coincide en afirmar que la EAE no es susceptible de impugnación autónoma ya que no es un acto de trámite cualificado al no decidir directa o indirectamente el fondo del asunto y difícilmente podría argüirse que produzca indefensión o perjuicio irreparable a derechos o intereses legítimos. Por tanto, la EAE no es decisoria, no es vinculante y en consecuencia no es impugnable.

Ahora bien, el hecho de que no sea vinculante no tiene porqué excluir que decida directa o indirectamente el fondo del asunto, en este caso el contenido del plan. De hecho el resultado de la EAE debe incorporarse, debe tenerse en cuenta en la decisión, en la aprobación del plan por lo que una interpretación extensiva podría conducirnos a afirmar que sí decide indirectamente el fondo del asunto a pesar de no tener carácter vinculante. En cualquier caso, la discusión quizá sea inútil dado que cabe perfectamente la impugnación del plan con base en la presunta ilegalidad de la EAE llevada a cabo.

\footnotetext{
${ }^{94}$ LOZANO CUTANDA, Derecho Ambiental Administrativo cit., p.348.
} 


\section{Toma de decisión: propuesta de Plan o Programa}

El proceso de toma de decisión ha de tener en cuenta los resultados del proceso de evaluación de impacto ambiental. Por ello la propuesta del Plan o Programa, a elaborar por el órgano promotor, tomará en consideración el informe de sostenibilidad ambiental, las alegaciones formuladas y la memoria ambiental. La resolución definitiva del órgano sustantivo competente es el acto que pone fin al procedimiento principal, decidiendo motivadamente a la vista de todos los aspectos sobre la aprobación del plan o programa. La integración de las conclusiones de la memoria en el plan corresponde al promotor pero no existe un control por parte del órgano ambiental sobre cómo debe hacerlo, si bien deberá hacerlo siempre de manera transparente y razonable.

En el caso del Plan que nos ocupa, 2008-2016, el mismo fue aprobado por Acuerdo del Consejo de Ministros de 30 de mayo de 2008.

\section{Información sobre la decisión: publicidad.}

El Art. 14 LEAE establece que una vez aprobado el correspondiente plan o programa, el órgano promotor pondrá a disposición del órgano ambiental, de las Administraciones públicas afectadas, del público y de los Estados miembros consultados la siguiente documentación:

a) El plan o programa aprobado.

b) Una declaración que resuma los siguientes aspectos:

- De qué manera se han integrado en el plan o programa los aspectos ambientales.

- Cómo se han tomado en consideración el informe de sostenibilidad ambiental, los resultados de las consultas, incluyendo en su caso las consultas transfronterizas, la memoria ambiental, así como, cuando proceda, las discrepancias que hayan podido surgir en el proceso.

- Las razones de la elección del plan o programa aprobados, en relación con las alternativas consideradas.

c) Las medidas adoptadas para el seguimiento de los efectos en el medio ambiente de la aplicación del plan o programa.

d) Un resumen no técnico 
Esta previsión de obligada publicidad a la decisión que se adopte se enmarca dentro de la necesaria transparencia en la toma de decisiones ambientales y en facilitar el acceso al derecho la información ambiental mediante la correspondiente difusión del resultado de la planificación y la toma en consideración de los aspectos ambientales.

A juicio de JARIA I MANZANO, nos encontramos ante un supuesto de participación ambiental reconocido por la LEAE posterior a la adopción del plan o programa ${ }^{95}$, ya que permite a los ciudadanos hacer un seguimiento de la variable ambiental en el programa y llevar cabo una valoración de la eficacia del proceso de EAE, si bien desde el punto de vista formal no se prevé la participación del público en el seguimiento del plan o programa.

\section{Supervisión o seguimiento y ausencia de un régimen sancionador.}

La EAE establece que los órganos promotores deberán realizar un seguimiento de los efectos en el medio ambiente de la aplicación o ejecución de los planes y programas, para identificar con prontitud los efectos adversos no previstos y permitir llevar a cabo las medidas adecuadas para evitarlos. El órgano ambiental correspondiente participará en el seguimiento de dichos planes o programas. Para evitar duplicidades podrán utilizarse mecanismos de seguimiento ya existentes.

En el caso del Plan 2008-2016, en él se señala que con objeto de realizar un seguimiento de los indicadores que se incluyen en la memoria ambiental, se prevé elaborar, a lo largo del horizonte de la planificación, un informe anual en el que se recogerá la evolución de los mismos a medida que se vayan poniendo en servicio las distintas infraestructuras. De este modo, se podrá realizar un seguimiento de los efectos ambientales a través de los indicadores propuestos en la Memoria Ambiental ${ }^{96}$.

\footnotetext{
95 JARIA I MANZANO, “La participación del público...” cit. p. 221.

${ }^{96}$ Los indicadores que serán evaluados son:

- Los indicadores asociados a la planificación indicativa: Producción y Consumo energético; Cumplimiento de Compromisos Internacionales; Intensidad energética de la economía (tep/M€ PIB); Consumo de energía primaria (Mtep); Consumo de energía final a partir de fuentes renovables (Mtep); Generación de energía eléctrica a partir de fuentes renovables (GWh); Producción de energía en forma de biocombustibles (Mtep); Planificación de los sectores de electricidad y gas 2008-2016; Efecto invernadero, cambio climático y contaminación; Emisiones totales de gases de efecto invernadero asociadas al sector energético (MtCO2)
}

- Los indicadores asociados a la planificación vinculante: Emisiones de gases de efecto invernadero asociadas a las instalaciones que pertenecen a la planificación vinculante; Producción total de residuos; Producción total de residuos tóxicos y peligrosos; Consumo de recursos y sobre-explotación; Número de 
En relación con este seguimiento es necesario destacar, como destaca la doctrina ${ }^{97}$, la inexistencia de previsión alguna en la LEAE de régimen sancionador alguno en caso de incumplimiento por parte de los planificadores de las prescripciones de la EAE que hayan sido incluidas en el plan o programa aprobados. Estamos sin duda ante una sino la única norma ambiental obligatoria que no prevé régimen sancionador alguno. La razón es obvia dado que estaríamos ante un supuesto de autosanción por parte de la misma Administración autora del plan $^{98}$. La ausencia de un régimen sancionador conlleva también la inexistencia de previsiones relativas a la posible suspensión de la ejecución o programa que carezca de la preceptiva EAE.

No obstante, la ausencia de una consecuencia sancionadora al incumplimiento no evita que tal incumplimiento pueda ser impugnado ante la propia Administración o ante la jurisdicción contencioso-administrativa ya que las prescripciones ambientales contenidas en un plan por exigencia de la EAE sí tienen carácter obligatorio caso de que el citado plan se lleve a cabo en sus previsiones.

Estas son las fases que prevé con carácter general la LEAE para el procedimiento de evaluación ambiental de planes y programas. Una vez establecidos estos criterios básicos la LEAE establece de manera detallada el procedimiento de EAE respecto de los planes y

instalaciones que pueden contaminar el suelo; Superficie ocupada por instalaciones que pueden contaminar el suelo; Conservación de la biodiversidad; Ocupación de espacios protegidos y Red Natura 2000; Longitud de cables submarinos; Ocupación del área de distribución de especies en peligro de extinción o vulnerables; Ocupación de las áreas de críticas de especies en peligro de extinción

Además, dependiendo del sector energético eléctrico o gasista y de la infraestructura concreta de que se trate se calcularán los indicadores que se muestran a continuación. Para alguno de ellos es necesaria la aportación de información por parte de terceros. Son:

- Los indicadores de Impacto: Efecto invernadero, cambio climático y contaminación; Emisiones totales de gases acidificantes y eutrofizantes; Consumo de agua de refrigeración; Consumo de recursos y sobreexplotación; Ocupación de dominio público hidráulico; Cruces con la red hídrica de líneas de transporte de energía; Superficie de suelos contaminados; Salud; Población residente en las inmediaciones de instalaciones contaminantes; Inducción de riesgos ambientales; Número de accidentes; Vertidos accidentales de hidrocarburos;; Espacios sensibles potencialmente afectados por accidentes graves; Población potencialmente afectada por accidentes graves; Conservación de la biodiversidad; Ocupación de espacios sensibles; Vías de acceso en espacios protegidos y Red Natura 2000; Ocupación de ZEPIM y Red Natura 2000 en zonas costeras y marítimas; Ocupación de zonas de dominio público marítimo terrestre; Ocupación en cuadrículas de alta biodiversidad; Inducción de impactos en otros sectores y recursos; Ocupación de zonas y caladeros pesqueros; Ocupación de suelo de alto valor agrícola; Ocupación de masas boscosas; Ocupación de paisajes culturales; Superficie de las cuencas visuales; Inducción de riesgos ambientales; Ocupación de zonas con riesgo de erosión; Ocupación de zonas inundables; Ocupación de zonas con riesgo de incendios

${ }^{97}$ LOZANO CUTANDA, Derecho Ambiental Administrativo cit., p. 349; SANZ RUBIALES, "Notas..." cit., p.71.

${ }^{98}$ Algo que por cierto, ya la legislación de Evaluación de impacto ambiental excluye, previendo sanciones sólo para los supuestos de infractores promotores particulares, no cuando el infractor es la Administración como promotor de un proyecto sujeto a EIA. 
programas que son aprobados por el Estado y su Administración General, correspondiendo las competencias evidentemente al Ministerio de Medio Ambiente, actualmente denominado de Medio Ambiente, Desarrollo Rural y Marino.

\section{CONCLUSIÓN}

Como se ha puesto de manifiesto en nuestros días uno de los sectores económicos más relevantes pero con una mayor incidencia sobre el medio ambiente es el sector energético. Un sector que está sujeto a una planificación indicativa y vinculante $\mathrm{y}$ que necesariamente debe integrar la variable ambiental a través de un procedimiento de evaluación ambiental estratégica previsto en la legislación ambiental. Dada la relevancia y las consecuencias ambientales derivadas de la planificación energética, la EAE no puede circunscribirse a un mero trámite interno de la Administración planificadora a través del cual se cumplan los requisitos formales establecidos por la ley. Por el contrario es necesario integrar de manera real y efectiva la variable ambiental (principio de integración) en la planificación energética, adelantando las barreras de protección ambiental (principios de prevención y cautela) respecto de los ulteriores proyectos a los que sirve de marco, cumpliendo escrupulosamente con los criterios de gobernanza y transparencia en la toma de las decisiones públicas planificadoras con incidencia sobre el medio ambiente (principios de información y participación) y todo ello con un necesario control y seguimiento que posibiliten incluso el acceso a la justicia ambiental caso de incumplimiento.

\section{BIBLIOGRAFÍA}

ALLI ARANGUREN, J.C., "La evaluación ambiental estratégica en la Ley Foral 4/2005, de 2 de marzo, de intervención para la protección ambiental", Revista jurídica de Navarra, núm. 41, 2006.

ARIÑO ORTIZ, G., Principios de Derecho Público Económico, Comares, Granada, 1999.

BETANCOR RODRÍGUEZ, A., Instituciones de Derecho Ambiental, La Ley, Madrid, 2001. 
- Mejorar la regulación. Una guía de razones y medios, Fundación Rafael del Pino-Marcial Pons, Madrid, 2009.

BARNÉS, J., "Sobre el procedimiento administrativo evolución y perspectivas", en Barnés, J. (ed.), Innovación y reforma en el Derecho Administrativo, Global Law Press, Sevilla, 2006.

CALANCHA MARZANA, F., en VVAA, Manual del Sector de Hidrocarburos, Aranzadi, Cizur Menor, 2008.

CALVO HERRERO, R. "Evaluación estratégica ambiental de planes y programas", Revista interdisciplinar de gestión ambiental, núm. 24, 2000.

— "La nueva normativa sobre Evaluación Ambiental de Planes y Programas y su relación con lo regulado al respecto por alguna Comunidad Autónoma", Ecosostenible, núm. 23, 2006.

CERRILLO i MARTÍNEZ, A. (AAVV) La gobernanza hoy: 10 textos de referencia, INAP, Madrid, 2005.

DE LA CRUZ FERRER, J. "La liberalización de los servicios públicos y el sector eléctrico” Marcial Pons, 1999.

— "El funcionamiento del sistema eléctrico. Sujetos. Separación de actividades. Planificación”, Muñoz Machado, S., Serrano González, M., Bacigalupo Sagesse, M. (dirs.), Derecho de la regulación económica. III. Sector energético, vol. I, Iustel, Madrid, 2009.

DELGADO-IRIBARREN GARCÍA-CAMPERO, M. “El Plan Energético Nacional (PEN) 1983”, RAP, núm. 104, 1984.

DEL GUAYO CASTIELlA, I., El servicio público del gas. Producción, transporte y suministro. Marcial Pons, Madrid, 1992.

DÍAZ LEMA, J.M., “Sector energético: política y derecho”, Serie Ensayos-6, Mallorca, 1984.

DOMINGO LÓPEZ, E., "Régimen jurídico de las energías renovables y la cogeneración eléctrica”, MAP, Madrid, 2000. 
ENTRENA RUIZ, D., "La Ley 9/2006, de 28 de abril, sobre evaluación de los efectos de determinados planes y programas en el medio ambiente: contenido y consecuencias, en particular en el ámbito urbanístico", Ecosostenible, núm. 16, 2006.

FABRA UTRAY, J., ¿Liberalización o regulación? Un mercado para la electricidad, Marcial Pons, Madrid, 2004.

FERNANDEZ TORRES, J.R., La evaluación ambiental estratégica de planes y programas urbanísticos, Aranzadi, Cizur Menor, 2009.

FERNÁNDEZ VALVERDE, R., "Evaluación ambiental estratégica", Estudios de derecho judicial, núm. 82, 2005.

GALERA RODRIGO, S., La evaluación ambiental de planes y programas, Montecorvo, 2006.

GARCÍA BELLIDO, J., "Hacia un nuevo control democrático de la planificación territorial: la evaluación ambiental estratégica de planes y programas", Ciudad y Territorio, Estudios Territoriales, 2002.

GARRIDO CUENCA, N., "La evaluación ambiental estratégica de políticas, planes y programas", Revista Aranzadi de derecho ambiental, núm. 5, 2004.

GÓMEZ MONTORO, A.J., LÓPEZ-JURADO, F.B “Los principios constitucionales referidos al ordenamiento jurídico español" en Becker, F., Cazorla, L.M., MartínezSimancas, J., Sala, J. M. (dirs.), Tratado de Regulación del Sector Eléctrico, Aranzadi, Cizur Menor, 2009.

GONZÁLEZ ESPEJO, A. "Cuestiones jurídica asociadas a la planificación energética" en La nueva regulación eléctrica. VII Jornadas jurídicas del sector eléctrico, Civitas, Madrid, 2002

— en López-Ibor Mayor, V., Beneyto Pérez, J. (dirs.), Comentarios a las Leyes Energéticas, Civitas, Madrid, 2006.

GUILLÉN CARAMÉS, J. "Marco y régimen de las actividades del sector gasista en la Ley del Sector de Hidrocarburos", Muñoz Machado, S., Serrano González, M., Bacigalupo Sagesse, M. (dirs.), Derecho de la regulación económica. III. Sector energético, vol. II, Iustel, Madrid, 2009,

HOPPE, W. "Planificación”, Documentación Administrativa, núm. 235-236, 1993. 
JARIA I MANZANO, J., "La participación del público en la evaluación ambiental estratégica”, Revista Aranzadi de derecho ambiental, núm. 11, 2007.

LOPERENA ROTA, D., Los principios del Derecho Ambiental, Civitas, Madrid, 1998.

LÓPEZ RAMÓN, F. "Infraestructuras de energía y ordenación del territorio", El derecho de la energía. XV Congreso italo-español de profesores de Derecho administrativo, IAAP, Sevilla, 2006.

— (coord.) Observatorio de Politicas Ambientales 2009, Aranzadi, Cizur Menor, 2009 (y anteriores).

LÓPEZ SAKO, M.J., Regulación y autorización de parques eólicos, Civitas, Madrid, 2009.

LOZANO CUTANDA, B. Derecho Ambiental Administrativo, Dykinson, Madrid, $2008^{9}$.

MANTECA VALDELANDE, V., "Evaluación ambiental de planes y programas" Actualidad administrativa, núm.1, 2007.

MARTÍN MATEO, R. Nuevo Derecho Energético, IEAL, Madrid, 1982.

— Nuevos instrumentos de tutela ambiental, Trivium, Madrid, 1994.

MARTÍN RETORTILlO, S., Derecho Administrativo Económico, tomo I, Madrid, 1988.

NIETO MORENO, J.E., “¿Protagonistas o actores de reparto? A propósito de los sujetos intervinientes en la evaluación ambiental de planes y programas", Revista Aragonesa de Administración Pública, núm. 31, 2007.

— "La transposición de la Directiva 2001/42/CE: modelos y cuestiones abiertas" en Evaluación de Impacto Ambiental. Evolución normativo-jurisprudencial, cuestiones procedimentales y aplicación sectorial, (AAVV) Atelier, Barcelona, 2009.

NOGUEIRA LÓPEZ, A., “¿Participación efectiva o quimera procedimental?”, VVAA, Evaluación de Impacto Ambiental. Evolución normativo-jurisprudencial, cuestiones procedimentales y aplicación sectorial, Atelier, Barcelona, 2009.

PALLARÈS SERRANO, A., La planificación hidrológica de cuenca como instrumento de ordenación ambiental sobre el territorio, Tirant lo Blanch, Valencia, 2007. 
RAZQUIN LIZARRAGA, J.A., "Evaluación ambiental de planes y programas", Lozano Cutanda, B., Alonso García, E. (dirs.), Diccionario de Derecho Ambiental, Iustel, Madrid, 2006.

RAZQUIN LIZARRAGA, J.A., RUIZ DE APODACA ESPINOSA, A., Información, participación y acceso a la justicia en materia de medio ambiente. Comentario sistemático a la Ley 27/2006, de 18 de julio, Aranzadi, Cizur Menor, 2007.

ROSA MORENO, J., "La evaluación ambiental estratégica en la planificación de infraestructuras”, III Congreso Nacional de Derecho Ambiental, 2000.

RUIZ DE APODACA ESPINOSA, A., "Los condicionantes ambientales en la implantación de instalaciones de generación de energía eléctrica", Noticias de la Unión Europea, núm. 284, 2008, pp. 77-91.

SCHMIDT-EICHSTAEDT, G., "La Directiva 2001/42/CE, sobre evaluación ambiental estratégica, apuntes desde la República Federal de Alemania”, en Revista Aranzadi de Derecho Ambiental, núm. 4, 2003.

SALAS HERNÁNDEZ, J., "La Energía", Martín Retortillo, S. (dir.), Derecho Administrativo Económico II, La Ley, Madrid, 1991.

SALMADOR SEGURA, J., en López-Ibor Mayor, V., Beneyto Pérez, J. (dirs.), Comentarios a las Leyes Energéticas, Civitas, Madrid, 2006.

SÁNCHEZ GUTIÉRREZ, M.M., La regulación del sector del gas natural, Tirant lo Blanch, Valencia, 2006.

SANZ RUBIALES, I., "Notas sobre el régimen jurídico de la evaluación estratégica de planes en la Ley 9/2006”, Revista Aranzadi de derecho ambiental, núm. 12, 2007.

SOLER TAPPA, E., Derecho de la Energía. Dictámenes de la Abogacía del Estado en el Ministerio de Industria, Vol. I, Civitas, Madrid, 2008.

TORNOS MAS, J. "La distribución de competencias en el sector energético”, Muñoz Machado, S., Serrano González, M., Bacigalupo Sagesse, M. (dirs.), Derecho de la regulación económica. III. Sector energético, vol. I, Iustel, Madrid, 2009.

TRILLO-FIGUEROA, J., LÓPEZ-JURADO ESCRIBANO, F.B., La regulación del sector eléctrico, Civitas, 1996. 
VERDÚ AMORÓS, M., "Una visión sintética del significado de la evaluación ambiental estratégica", Revista Aranzadi de derecho ambiental, núm. 10, 2006.

- Ámbito de aplicación y procedimiento de la evaluación ambiental estratégica, Aranzadi, Cizur Menor, 2008.

YAÑEZ DÍAZ, C., "La evaluación ambiental de los planes y programas en la normativa estatal y madrileña”, Revista jurídica de la Comunidad de Madrid, núm.23, 2006. 